\title{
ESTRATEGIA DE SEGURIDAD Y DEFENSA DE LOS ESTADOS UNIDOS DE AMÉRICA ${ }^{1}$
}

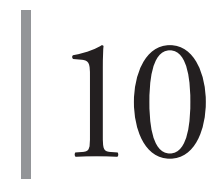

\author{
Yesid Eduardo Ramírez Pedraza \\ Stefany García Sintura
}

\section{Introducción}

La Estrategia de Seguridad Nacional de los Estados Unidos es un documento del más alto nivel, en el que la administración presidencial norteamericana plasma su visión del mundo, valora las oportunidades y amenazas que se derivan de ese contexto externo, y enuncia de un modo muy general cómo se planea afrontarlos, siempre con el objetivo final de preservar los intereses nacionales, entre los que se incluye el continuar siendo la nación líder del mundo globalizado (Instituto Español de Estudios Estratégicos - IEEE, 2010).

Dicho documento es formulado por la rama ejecutiva del gobierno de los Estados Unidos y se convierte en la declaración integral que articula los intereses, metas y objetivos de la nación, indispensables para su seguridad, así mismo, también se convierte en la doctrina que aplicará el Presidente en su política exterior (National Security Strategy Archive, 2018).

A través de la historia, Estados Unidos ha formado una estrategia de corte neoconservador, que lo ha posicionado como un estado hegemónico en el sistema internacional, teniendo en cuenta que el poder no se mide en valores absolutos, sino en la capacidad de un estado de transformar ese poder puramente material

1 Este Capítulo del Libro hace parte del Proyecto de Investigación de la Maestría en Seguridad y Defensa Nacionales, titulada "Desafíos y Nuevos Escenarios de la Seguridad Multidimensional en el Contexto Nacional, Regional y Hemisférico en el Decenio 2015-2025”, el cual hace parte del Grupo de Investigación Centro de Gravedad de la Escuela Superior de Guerra "General Rafael Reyes Prieto", reconocido y categorizado en (A) por Colciencias, con el código COL0104976. 
en influencia o en liderazgo (Borda, 2013), por lo que el cambio sustancial en la distribución del poder económico o militar a escala internacional no ha afectado la habilidad de Estados Unidos para lograr lo que quiere a un costo bajo, preferiblemente, a través de la disuasión y no del uso real del poder material.

Desde la intervención de Estados Unidos en la Primera (aliado - 1914 a 1918) y Segunda Guerra Mundial (aliado - 1939 a 1945), se configuraron los elementos básicos de su estrategia de seguridad nacional como la contención de amenazas externas, específicamente de otros Estados-nación, sin embargo, con la aparición de armas nucleares, se evidenció que existen problemas globales que trascienden las clásicas fronteras nacionales y deben ser prevenidas, extendiendo así el concepto de la defensa contra la agresión como era la concepción tradicional.

Lo anterior, sumado a la confrontación con el enemigo socialista en la Guerra Fría, hizo que Estados Unidos asumiera una postura intervencionista en aspectos económicos y militares, a través de acuerdos internacionales para tener acceso a bases militares en el exterior, como medio más seguro de controlar posibles conflictos en las zonas más alejadas del territorio estadounidense, especialmente, si coinciden con recursos estratégicos (Campins Rahan, 2004).

Durante estos años, Estados Unidos concebía su seguridad nacional como la defensa militar ante amenazas militares, privilegiando su dimensión internacional, pero de igual forma contemplaba aspectos políticos, económicos y domésticos que daban paso a una agenda de seguridad que resaltaban los intereses y valores de la cultura estadounidense (supervivencia, justicia, libertad, democracia, prosperidad, prestigio y promoción de la ideología nacional) (Montero Moncada, 2006, p. 111).

Pero es el 11 de septiembre de 2001, la coyuntura que logra modificar los intereses vitales y secundarios estadounidenses, creando un discurso antiterrorista mundial, que le permitió a Estados Unidos identificar una serie de aliados para enfrentar Estados hostiles, que alojaban agrupaciones terroristas (Montero Moncada, 2006, p. 107).

Así, Estados Unidos ha liderado los procesos de construcción conceptual de la seguridad, plasmando en sus documentos oficiales y en la postura de organismos internacionales donde ejerce influencia, las propuestas para ampliar la idea netamente militar hacia una visión multidimensional de la seguridad, proponiendo un cambio de paradigma que articule las estrategias de seguridad ubicando al ser humano en el centro de las políticas públicas internacionales (Font \& Ortega, 2012). Así como lo expresa Abraham Stein (2003), el concepto de seguridad multidimensional quedó definitivamente establecido en la Conferencia Especial sobre Seguridad con la Declaración sobre Seguridad en las Américas: 
"El fundamento y razón de ser de la seguridad es la protección de la persona humana... Las condiciones de la seguridad humana mejoran mediante el pleno respeto de la dignidad, los derechos humanos y las libertades fundamentales de las personas, así como mediante la promoción del desarrollo económico y social, la inclusión social, la educación y la lucha contra la pobreza, las enfermedades y el hambre...el concepto y los enfoques tradicionales deben ampliarse para abarcar amenazas nuevas y no tradicionales, que incluyen aspectos políticos, económicos, sociales, de salud y ambientales...” (Organización de los Estados Americanos, 2003).

A partir de este nuevo concepto de la seguridad fueron identificadas amenazas como el terrorismo, la delincuencia organizada transnacional, las drogas, la corrupción, el lavado de activos, el tráfico ilícito de armas, la pobreza y la exclusión social, los desastres naturales y de origen humano, los riesgos a la salud humana, el deterioro del medio ambiente, la trata de personas, los ataques cibernéticos, accidentes marítimos con materiales potencialmente peligrosos y la posibilidad del acceso, posesión y uso de armas de destrucción masiva y sus medios por parte de terroristas (Stein, 2009) (Páez Murillo, Peón Escalante \& Ramírez Pedraza, 2018).

Todo lo anterior ha sido potencializado por el fenómeno de la globalización, gracias a redes ágiles, multinacionales y con recursos necesarios que le impiden a los gobiernos crear y adoptar nuevas estrategias para hacer frente a estos desafíos (Naím, 2003), pese a los esfuerzos de la comunidad internacional por formular políticas mundiales a problemas mundiales (Naciones Unidas, 2004) y la cooperación, apoyo y ayuda técnica de países como Estados Unidos, los grupos delictivos han avanzado gracias a las condiciones sociales y económicas de países débiles.

Finalmente, es necesario reconocer el trabajo de Estados Unidos en la construcción de unos objetivos geoestratégicos y en el mantenimiento de un sistema internacional que favorezca los intereses de la nación; pese a su gran tradición, la actual Estrategia Nacional de Seguridad (National Security Strategy of the United States of America) publicada en diciembre de 2017 por el presidente Donald Trump, dio un viraje al resaltar el evidente escenario de competencia desde el punto de vista geopolítico, lo que ha implicado el incremento de las luchas por el poder, con multitud de amenazas y riesgos transnacionales provenientes tanto de otros Estados como de actores no estatales, sin embargo, Trump y su estrategia "Primero América”, ha reducido y limitado el perfil global de los Estados Unidos como modo de aminorar el coste y los riesgos, aunque sea a través de una disminución del nivel de ambición del país (Laborie, 2018), pero lo anterior no es compatible con los discursos que el presidente ha dado públicamente, donde se observan los impulsos proteccionistas - aislacionistas y a su vez, el deseo de competencia tripolar entre Estados Unidos, China y Rusia (Benedicto, 2018). 
Dicha postura estadounidense proviene de su declive económico y de poder, provocado por relaciones comerciales deficitarias, sobrecostos derivados de garantizar la seguridad a sus aliados de la OTAN y el Pacífico e intervenir militarmente en Oriente Medio (Instituto Español de Estudios Estratégicos, 2017). Ahora el elemento vertebral de la política exterior estadounidense, lo constituyen una serie de grandes pactos bilaterales con China y Rusia y el resto de potencias, asentados en un liderazgo personalista eventualmente recurriendo a coaliciones ad hoc para intervenciones militares puntuales, estrictamente aquellas que se consideran imprescindibles para defender los intereses vitales de Estados Unidos.

\section{Desarrollo}

\subsection{El contenido (análisis descriptivo)}

La actual Estrategia de Seguridad Nacional, expedida por el presidente Donald Trump en diciembre de 2017, se desarrolla a través de cuatro pilares estratégicos y su aplicación regional, a saber (The White House, 2017):

- Pilar I: proteger al pueblo estadounidense, a la patria y el estilo de vida estadounidense.

Para ello, el Gobierno se propone asegurar las fronteras a través de la defensa contra las armas de destrucción masiva (ADM), el combate en Biothreats (bacterial control technology) y contra pandemias y fortalecer la política de inmigración y control fronterizo. Así mismo, persigue a la amenaza, principalmente la derrota de los terroristas yihadistas y el desmantelamiento de organizaciones criminales trasnacionales. Finalmente, en este pilar se busca mantener a los Estados Unidos a salvo en la era cibernética y promover su resiliencia.

- Pilar II: promover la prosperidad Americana.

En este aspecto, lo que se requiere es rejuvenecer la economía doméstica, promover las relaciones económicas libres, justas y recíprocas, liderar procesos de tecnología, invención e innovación, promover y proteger la Base de Innovación de Seguridad Nacional y recuperar el dominio de la energía.

- Pilar III: preservar la paz a través de la fuerza.

Estados Unidos con su actual gobierno, busca renovar sus ventajas competitivas, así como sus capacidades (militar, Base Industrial de Defensa, fuerzas 
nucleares, espacio, ciberespacio, inteligencia); adicionalmente busca fortalecer su diplomacia y política a través de la diplomacia competitiva, las herramientas de la diplomacia económica y la información política.

- Pilar IV: Influencia Americana.

Para ello buscará fortalecer la estrategia para convertir en socios algunos países aspirantes, así mismo, mejorará los resultados en los foros multilaterales y resaltará los valores americanos a nivel mundial.

- La estrategia en un contexto regional

Finalmente, Trump ha priorizado su estrategia de manera focalizada determinando sus intereses en las regiones indo-pacífico, Europa, Medio Este, Asia Meridional y Central, hemisferio oeste y África.

En virtud de lo anterior, es fundamental que la declaración de intereses del Presidente Trump, supone un instrumento de política pública que brinda al sector defensa (Departamento de Defensa y Fuerzas Militares) las expectativas del gobierno acerca de sus funciones, ofreciendo igualmente el fundamento necesario para la asignación de recursos o financiamiento previsible que constituyen un auxiliar importante a los efectos de los procesos continuos de planificación de la defensa.

\subsection{Política y doctrina de defensa}

Los documentos políticos y estratégicos que orientan la seguridad y defensa de los Estados Unidos, se han estructurado desde el año de 1988, bajo el gobierno de Ronald Reagan y la expedición de la Estrategia de Seguridad Nacional de los Estados Unidos (National Security Strategy of the United States - NSS).

Jerárquicamente, la Estrategia de Seguridad Nacional es el documento más importante, al ser la declaración integral que articule los intereses, metas y objetivos para la seguridad de los Estados Unidos. Anualmente, el Presidente presenta al Congreso un informe sobre el cumplimiento de dicha estrategia al igual que una propuesta de presupuesto, garantizando así la formulación de una estrategia coherente e integrada a medio o largo plazo de los intereses vitales para la seguridad nacional. Los objetivos de la NSS son:

- Comunicar la visión estratégica del Ejecutivo al Congreso y, por lo tanto, lograr su respaldo ante solicitudes de financiamiento.

- Comunicar la visión estratégica del Ejecutivo a las unidades constitutivas extranjeras, especialmente a los gobiernos que no están en la agenda de la cumbre de los EE. UU. 
- Comunicar con públicos internos selectos, como los partidarios políticos que buscan el reconocimiento presidencial de sus problemas, y aquellos que esperan ver una estrategia coherente y previsora que puedan apoyar.

- Crear un consenso interno sobre política exterior y de defensa dentro del poder ejecutivo.

- Contribuir a la agenda general del Presidente, tanto en términos de contenido como de mensajería.

Además, la NSS determina la doctrina general que el Presidente aplicará en su política exterior. A continuación, se determinan las principales estrategias de seguridad nacional a través de las diferentes administraciones:

Tabla No 1. Estrategias de Seguridad Nacional de Estados Unidos

\begin{tabular}{|c|c|c|}
\hline AÑ & ADMINISTRACIÓN & NATIONAL SECURITY STRATEGY \\
\hline 2017 & Donald Trump & National Security Strategy of the United States \\
\hline 2015 & Barack Obama & National Security Strategy \\
\hline 2010 & Barack Obama & National Security Strategy \\
\hline 2006 & George W. Bush & $\begin{array}{l}\text { The National Security Strategy of the United States of } \\
\text { America }\end{array}$ \\
\hline 2002 & George W. Bush & $\begin{array}{l}\text { The National Security Strategy of the United States of } \\
\text { America }\end{array}$ \\
\hline 2001 & Bill Clinton & A National Security Strategy For A Global Age \\
\hline 2000 & Bill Clinton & A National Security Strategy For A New Century \\
\hline 1996 & Bill Clinton & $\begin{array}{l}\text { A National Security Strategy of Engagement and En- } \\
\text { largement }\end{array}$ \\
\hline 1993 & George H.W. Bush & National Security Strategy of the United States \\
\hline 1991 & George H.W. Bush & National Security Strategy of the United States \\
\hline 1988 & Ronald Reagan & National Security Strategy of the United States \\
\hline
\end{tabular}

Fuente: The National Security Strategy Report

De la NSS se desprenden otros documentos estratégicos a nivel nacional y otros a nivel sectorial, la Estrategia de Defensa Nacional (The National Defense Strategy - NDS) establece los objetivos y planes para la estructura de la fuerza militar, su modernización, los procesos comerciales, la infraestructura de apoyo 
y los recursos necesarios (humanos y financieros) y todo lo que se requiere para apoyar la Estrategia de Seguridad Nacional (NSS). La NDS es formulada por el Departamento de Defensa, proporcionando las orientaciones estratégicas para las campañas y planes de contingencia y el desarrollo de la fuerza y sistema de inteligencia. Los resultados de dicha estrategia se rinden en el Examen Cuadrienal de Defensa (Quadrennial Defense Review - QDR).

En los últimos años, el Departamento de Defensa de los Estados Unidos (DoD) ha incluido en la NDS, la necesidad de fortalecer las alianzas y construir unas nuevas para vencer el terrorismo global y prevenir ataques contra Estados Unidos, sus aliados y amigos, así como las amenazas con armas de destrucción masiva $(\mathrm{ADM})$ y la desactivación de conflictos regionales incluyendo las intervenciones en diferentes regiones del mundo. Finalmente cabe resaltar que es el documento de NDS, el que evalúa el entorno estratégico, los desafíos y los riesgos y traza el camino a seguir para el cumplimiento de los objetivos de la NSS.

Otro documento de relevancia es la Estrategia Militar Nacional (National Military Strategy - NMS), la cual apoya los objetivos de la NSS y aplica la NDS, describiendo el plan de las Fuerzas Armadas para lograr objetivos militares a corto plazo, además de garantizar a largo plazo que sigan siendo decisivos. Además, la NMS brinda una orientación estratégica sobre cómo las Fuerzas deben alinear los fines militares, las formas, los medios y los riesgos. La particularidad de dicho documento es que no tiene el carácter obligatorio de la NSS y la NDS.

\subsection{Evaluación del entorno de seguridad y del contexto interno}

El entorno estratégico en el cual se formuló la Estrategia de Seguridad Nacional de los Estados Unidos de la era Trump es bastante complejo y se ha caracterizado por el surgimiento de la competencia estratégica a largo plazo entre algunos Estados, lo anterior ha significado una evaluación de las amenazas de la agenda internacional, por ejemplo, quitando preponderancia al terrorismo y dándosela al control de poderes revisionistas como Rusia, China, Corea del Norte e Irán, todas estas naciones, según la Estrategia de Estados Unidos, buscan formar un mundo consistente con su modelo autoritario, ganando autoridad y veto sobre decisiones económicas, diplomáticas y de seguridad en otras naciones (Department of Defense, 2018, p. 2).

Por su parte, China ha aprovechado su modernización militar, las operaciones de influencia que realiza y la economía predatoria que maneja, para forzar a sus vecinos y reordenar la región indo-pacífica en su beneficio (Ardila Castro \& Rodríguez, 2018). Al mismo tiempo, Rusia busca autoridad en su periferia para acabar con la OTAN, cambiar el régimen de seguridad en Europa y Medio Oriente 
y disponer de estructuras económicas a su favor (un ejemplo de lo anterior fue el uso de sus medios para desacreditar y subvertir los procesos democráticos en Georgia, Crimea y el este de Ucrania) que combinados con el arsenal nuclear denotan un desafío en expansión (Fernandez-Osorio, 2015).

Otro cambio en el entorno estratégico es un orden internacional resistente pero debilitado después de la Segunda Guerra Mundial; Estados Unidos aún considera su red de aliados y socios, su columna vertebral en el mantenimiento de la seguridad global, sin embargo, regímenes como el de Corea del Norte e Irán han desestabilizado el orden internacional, socavando los principios y reglas de juego, en algunos casos patrocinando el terrorismo y en otros fortaleciendo su programa o proyecto de misiles de largo alcance que logren una influencia coercitiva en sus regiones (Department of Defense, 2018, p. 5).

Los desafíos a la ventaja militar de Estados Unidos representan otro cambio en el entorno de seguridad. Se podían desplegar fuerzas cuando se quisiera, donde se quisiera y operar como se quisiera, hoy en día, todos los dominios (aire, tierra, mar, espacio y ciberespacio) son más letales y perturbadores, logrando una combinación en un teatro de operaciones total, cualquier lugar del mundo. A lo anterior se suman, los rápidos avances tecnológicos (análisis de big data, inteligencia artificial, robótica, inteligencia artificial, biotecnología, entre otros) y el carácter cambiante de la guerra que ponen de manifiesto el interés de Estados Unidos en mantener una ventaja tecnológica que requerirá cambios en la industria, diversificación de las fuentes de inversión y la protección de la seguridad nacional a través de una base de innovación (Department of Defense, 2018, p. 6).

Finalmente, se mantiene la preocupación por la proliferación de actores no estatales (grupos terroristas, delincuencia trasnacional, hackers cibernéticos) que amenazan el entorno de seguridad con capacidades de injerencia masiva en asuntos mundiales; el terrorismo que sigue siendo una condición persistente impulsada por la ideología y la inestabilidad política; el riesgo de afectación de la infraestructura crítica de la nación y las armas de destrucción masiva (ADM) (Department of Defense, 2018, p. 7).

\section{Estrategia de reacción frente a peligros percibidos y de cumplimiento de compromisos internacionales (alianzas y coaliciones)}

A través de la historia, Estados Unidos ha logrado soportar sus intereses con una estrategia atractiva a otros Estados y organizaciones que defienden y promueven 
la libertad y la democracia, pero que a su vez buscan su seguridad. El presidente Donald Trump, asegura que no impondrá los valores estadounidenses, sino que, a través de sus alianzas, asociaciones y coaliciones, basados en el libre albedrío y los intereses compartidos, desarrollará políticas que permitan alcanzar las metas propias mientras sus socios alcanzan las suyas. La red de aliados y socios ha sido una gran fortaleza para incrementar las capacidades políticas, económicas, militares, de inteligencia y de otro tipo de los Estados Unidos (The White House, 2017, p. 37).

Adicionalmente, la nueva Estrategia de Seguridad Nacional alienta a nuevos países para que se conviertan en socios de Estados Unidos. Estos socios aspirantes incluyen estados que son frágiles (The White House, 2017, p. 38), que se están recuperando de un conflicto y buscan un camino hacia la seguridad sostenible y el crecimiento económico, aumentando las oportunidades económicas para Estados Unidos a través de mercados rentables para las empresas estadounidenses, así mismo, ayudando a conseguir balances de poder regional favorables y socios de coaliciones para compartir cargas y abordar una variedad de problemas en todo el mundo.

El apoyo estadounidense a los socios aspirantes permitió la recuperación de países de Europa Occidental bajo el Plan Marshall, así como la integración continua de Europa Central y Oriental en las instituciones occidentales después de la Guerra Fría. En Asia, Estados Unidos trabajó con Corea del Sur y Japón, países devastados por la guerra, para ayudarlos a convertirse en democracias exitosas y entre las economías más prósperas del mundo (The White House, 2017, p. 39).

Sin embargo, hoy Estados Unidos debe competir por relaciones positivas en todo el mundo; por un lado, China está invirtiendo miles de millones de dólares en infraestructura en todo el mundo y por el otro, Rusia también proyecta su influencia de manera económica, a través del control de energía clave y otras infraestructuras en partes de Europa y Asia Central. Estados Unidos, por su parte ofrece una alternativa a las inversiones estatales que a menudo dejan en peor situación a los países en desarrollo, además se propone pasar de depender de la asistencia basada en subvenciones a enfoques que comprometan el capital privado y catalicen la actividad del sector privado. No se debe olvidar que la asistencia para el desarrollo que ha brindado Estados Unidos, respalda sus intereses nacionales, buscando una alineación internacional que genere mayor impacto.

El gobierno Trump ha establecido en la NSS tres acciones prioritarias para incrementar su influencia en países en desarrollo: 1) movilizar recursos, modernizando sus herramientas financieras e incentivando sus empresas para capitalizar en dichos países; 2) capitalizar en nuevas tecnologías, sobre todo en programas diplomáticos y de desarrollo, garantizado que la ayuda llegue al destinatario previsto; 
3) incentivar las reformas utilizando la diplomacia y la asistencia para alentar a los gobiernos a tomar mejores decisiones en temas de gobernanza, estado de derecho y desarrollo sostenible; actualmente Estados Unidos lo viene realizando a través de Millennium Challenge Corporation, que selecciona los países que están comprometidos con la reforma y luego supervisa y evalúa sus proyectos (The White House, 2017, p. 39).

Así mismo, ha establecido estrategias de acción en estados frágiles: 1) comprometerse selectivamente, dando prioridad al fortalecimiento de estados donde sus debilidad o fallas aumentan las amenazas a Estados Unidos (ej. prevenir el resurgimiento de refugios para terroristas en Afganistán); 2) trabajar con los reformadores, dando suma relevancia a los programas que empoderan a los gobiernos, los ciudadanos y la sociedad civil; 3) empleo de herramientas diplomáticas, económicas y militares al mismo tiempo cuando se asiste a socios aspirantes (The White House, 2017, p. 40).

Por otra parte, Estados Unidos pretende mejorar su participación en foros y espacios multilaterales, liderando acuerdos que dan forma a las reglas que afectan sus intereses y valores. En esta esfera, Estados Unidos también encuentra una competencia considerable y deben mantener un statu quo que propenda por la libertad en el espacio exterior y el mundo digital, siendo vital para su prosperidad y seguridad el acceso libre a los mares y el espacio, el flujo de datos e internet abierta e interoperable que aporten al éxito de la economía estadounidense. Así como sucede con los aspirantes a socios, Estados Unidos ha priorizado su participación y esfuerzo en los escenarios que favorecen sus intereses, los de sus aliados y socios (The White House, 2017, p. 40).

En cumplimiento de lo anterior estipula las siguientes acciones prioritarias: 1) ejercitar liderazgo en órganos políticos y de seguridad. En este punto, se hace imperiosa la reforma a las Naciones Unidas, buscando enfatizar en el principio de responsabilidad compartida entre los miembros; 2) reformas a instituciones financieras y comerciales internacionales como el Fondo Monetario Internacional (FMI), el Banco Mundial y la Organización Mundial del Comercio (OMC), incluyendo alentar a los bancos de desarrollo multilaterales a invertir en proyectos de infraestructura de alta calidad que promuevan el crecimiento económico; y presionando para que dichos espacios sean espacios eficaces y vinculantes para enjuiciar prácticas comerciales desleales; 3) Estados Unidos debe asegurarse de que los dominios comunes (espacio, ciberespacio, aire y marítimo) permanezcan libres, proporcionando su liderazgo y tecnologías para configurarlos. Es importante destacar que, pese a que Estados Unidos respeta la resolución pacífica de controversias según el 
derecho internacional, utilizará todos sus instrumentos de poder para defender sus intereses en dichos dominios; 4) finalmente, protegerá una red de internet gratuita y abierta, con barreras mínimas para el intercambio global de información y servicios (The White House, 2017, p. 41).

Es preciso recalcar que todo tipo de alianza, coalición o postura internacional de Estados Unidos es crucial para el cumplimiento de NSS, proporcionando una ventaja estratégica duradera y asimétrica que hasta la fecha ningún competidor o rival puede igualar. Esta ventaja ha servido en tiempo de paz y guerra, por ejemplo, después de los ataques terroristas del 11 de septiembre, la OTAN invocó la cláusula de defensa mutua (artículo 5) contribuyendo a la legitimidad de los combates militares dirigidos por Estados Unidos desde entonces. De igual forma los socios y aliados han proporcionado equilibrios de poder favorables que disuaden la agresión y respaldan la estabilidad, han proporcionado capacidades y fuerzas complementarias, han brindado un respaldo con sistemas de base y logística, y han compartido su responsabilidad en la defensa común.

Finalmente, esta red de socios y aliados debe ser motivada, por ello, Estados Unidos cuenta con una estrategia de modernización de socios extranjeros a través de las priorizaciones de venta de equipos militares y el intercambio de conocimientos que permitan integrar las fuerzas de dichos países con sus conceptos, doctrinas y referentes que garanticen la interoperabilidad y construyan a su vez una fuerza más letal a nivel internacional.

\section{Funciones y misiones de las Fuerzas Armadas}

Las Fuerzas Armadas de los Estados Unidos cumplen funciones cruciales al defender el país contra todos los adversarios, mientras sirven a la Nación como baluarte y garante de la independencia y la seguridad. Funcionan dentro del sistema de relaciones cívico-militares y sirven bajo el control civil del Presidente (comandante en Jefe). Estas instituciones representan los más altos valores y estándares de la sociedad estadounidense (Joint Chiefs of Staff, 2017).

Sin embargo, es la misión permanente del Departamento de Defensa, proporcionar fuerzas militares creíbles en combate necesarias para disuadir la guerra y proteger la seguridad de la nación. Si la disuasión falla, la Fuerza Conjunta está preparada para ganar, reforzando las herramientas tradicionales de la diplomacia de los Estados Unidos. El DoD (Departamento de Defensa) ofrece opciones militares para garantizar que el Presidente y los diplomáticos estadounidenses negocien desde una posición fuerte. Sumado a lo anterior, la naturaleza de los desafíos a los 
que se enfrentan las Fuerzas Armadas requiere de un trabajo integrado con las agencias institucionales y multinacionales, así como de ganar socios en toda la gama de operaciones militares, fundamentales para consolidar su poder militar.

Empezando por su Ejército (U.S. Army), Estados Unidos se propone luchar y ganar las guerras que la nación emprende, proporcionando un dominio de la tierra rápido y sostenido a través de operaciones militares y en apoyo a los comandos combatientes (U.S. Army, 2018).

Del mismo modo, cuenta con una Armada que lleva a cabo operaciones navales, manteniendo, entrenando y equipando para el combate a las fuerzas navales; capaces de conseguir la victoria de la guerra, disuadir agresiones y mantener la libertad de los mares, garantizando a través de su presencia progresiva, la seguridad y disuasión en el dominio marítimo (The Secretary of the Navy, 2018). La Armada, el Cuerpo de Marines y Guardacostas se encuentran bajo el liderazgo del Departamento de Armada.

Finalmente, Estados Unidos crea la Fuerza Aérea para organizar, entrenar y equipar principalmente para operaciones aéreas ofensivas y defensivas prontas y sustantivas. La Fuerza Aérea será responsable de la preparación para la prosecución efectiva de la guerra, excepto cuando haya otras asignaciones y, de acuerdo con los planes integrados de movilización, con la expansión de los componentes en tiempo de paz para alcanzar las necesidades de la guerra (Department of State, 1947).

Es de suma importancia destacar que las funciones y misiones de las Fuerzas Armadas de Estados Unidos, tradicionalmente han consistido en la protección del Estado, su territorio y habitantes frente a agresiones externas, sin embargo, su evolución, le han permito asumir igualmente responsabilidades en el mantenimiento de la paz y la seguridad internacionales, la asistencia humanitaria en situaciones de posguerra o de desastres naturales o el brindar asesoramiento y experiencia técnica militar no solo a países aliados sino a organismos internacionales.

\subsection{Capacidades}

Reconociendo la naturaleza persistente de las amenazas terroristas, la Fuerza Conjunta debe ser capaz de operar de manera rentable contra amenazas menos sofisticadas. Para lograr estos objetivos, el Departamento de Defensa debe invertir en las siguientes capacidades prioritarias en un esfuerzo sostenido para consolidar la ventaja competitiva de Estados Unidos (Chief Financial Officer, 2018, ps. 2-5):

- Fuerzas nucleares: Estados Unidos modernizarála tríada nuclear, incluido el comando, el control y las comunicaciones nucleares y la infraestructura 
de apoyo. Incluye el desarrollo de opciones para contrarrestar las estrategias coercitivas de los competidores, basadas en el uso o amenaza de ataques nucleares o estratégicos no nucleares.

- Espacio y ciberespacio como dominios de guerra: priorizar las inversiones en resiliencia, reconstitución y operaciones para garantizar la capacidad de la Fuerza Conjunta en el espacio y el ciberespacio, incluso bajo sofisticados ataques multidominio. Así mismo, Estados Unidos invertirá en un conjunto completo de capacidades cibernéticas e integrará estas en la planificación militar y el desarrollo de conceptos del Departamento de Defensa. Dichas inversiones contribuirán a la disuasión al negar a los adversarios potenciales una ventaja de atacar los activos espaciales y ciberespaciales de los Estados Unidos.

- Comando, control, comunicaciones, computadoras e inteligencia, vigilancia y reconocimiento (C4ISR): prioridad a las redes y los ecosistemas de información resilientes, duraderos y federados desde el nivel táctico hasta el estratégico. Las inversiones también priorizarán las capacidades para obtener y explotar información, negar a los competidores las mismas ventajas y permitir que el $\mathrm{DoD}$ atribuya ataques no cinéticos y responsabilizar a los adversarios que intentan explotar la negación.

- Defensa de misiles: centrándose en las defensas de misiles estratificados y las capacidades disruptivas tanto para las amenazas de misiles de teatro como para las de misiles balísticos de Corea del Norte. En particular, se buscarán soluciones holísticas y rentables para contrarrestar la amenaza que representan los sistemas de misiles de los competidores.

- Letalidad conjunta en entornos controvertidos: la Fuerza Conjunta podrá atacar diversos objetivos dentro de entornos altamente controvertidos para destruir las plataformas de proyección de poder móvil desde el comienzo de un conflicto. Esto incluye capacidades para mejorar la letalidad de combate cuerpo a cuerpo en terrenos complejos. Igualmente, se prestará especial atención a las municiones, sus reservas y la modificación de las armas actuales para futuros conflictos.

- Maniobra de fuerza y resistencia a la postura: prioridad a las fuerzas terrestres, aéreas, marítimas y espaciales que puedan desplegar, operar y mantener operaciones en todos los dominios mientras se encuentren bajo ataque. Esto requerirá la transición de una postura pacífica de infraestructura grande, centralizada y no endurecida a una base flexible, dispersa, más pequeña, protegida por defensas activas y pasivas. 
- Sistemas autónomos avanzados: Estados Unidos invertirá ampliamente en la aplicación militar de la autonomía y la inteligencia artificial, incluida la aplicación rápida de avances comerciales, para obtener ventajas militares competitivas.

- Logística ágil y resistente: prioridad a las municiones existentes avanzadas preposicionadas, los activos de movilidad estratégica, el apoyo de socios y aliados, así como la logística y el mantenimiento distribuido para garantizar su efectividad mientras se esté bajo un ataque persistente de múltiples dominios.

Pero más allá de estas capacidades específicas, las Fuerzas Militares de Estados Unidos, requieren un cambio en su preparación, empleo y desarrollo que convierta realmente a la Fuerza Conjunta en una fuerza letal y que mantenga la proyección de poder militar en: municiones, modernización y disuasión nuclear, misiles de defensa, sistemas de defensa, operaciones en el ciberespacio, ciencia y tecnología, reconstrucción y capacidades conjuntas (Chief Financial Officer, 2018, ps. 3-4).

\subsection{Problemas presupuestario y de recursos (economía de defensa)}

Dentro de la Estrategia de Seguridad Nacional de Trump se estipularon unos pilares descritos anteriormente, en cumplimiento de ellos, se ha presentado el presupuesto para el año fiscal 2019 por parte del Departamento de Defensa, con esa propuesta pueden ser llevadas a cabo operaciones, mantener la preparación actual y avanzar hacia unas Fuerzas Militares más modernas, capaces y letales, que requieren de un financiamiento consistente, predecible y suficiente. Estados Unidos no puede permitir la incertidumbre e inestabilidad en la asignación de recursos financieros, y aquí radica el primer problema de presupuesto, impuesto por la Ley de Control Presupuestal de 2011 y que permite la asignación de recursos a través de resoluciones continuas (Chief Financial Officer, 2018, p. 8), que incluye posponer, retrasar e inhibir el desarrollo, adquisición y mantenimiento de sistemas de armas; ralentizando la acumulación de arsenales de municiones críticas e introduciendo la posibilidad de cierres del gobierno. La inestabilidad presupuestaria repercute negativamente en la capacidad del Departamento de trabajar de manera eficiente, rompiendo con los procesos de planificación a largo plazo y la asignación de recursos a programas o iniciativas que requieren de más de un año fiscal.

La Estrategia de Defensa Nacional (NDS) ha dado prioridad a la ventaja militar de Estados Unidos en relación con China y Rusia, y por tal razón, su solicitud de presupuesto busca aumentar la letalidad, resistencia, agilidad de las Fuerzas Militares, a la vez que construye un poder militar más flexible y dinámico que 
permita trabajar a través de aliados y socios y proyecten su capacidad global (Chief Financial Officer, 2018, ps. 2-3) para todo tipo de operaciones contra la gran variedad de amenazas del sistema internacional. Esta estrategia abarca las siguientes iniciativas:

- Aumento de la resistencia final para el Ejército, la Armada y la Fuerza Aérea.

- Continuación de la iniciativa Department's Missile Defeat and Defense Enhancement (MDDE).

- Aumento de la adquisición de municiones preferidas y avanzadas.

- Modernización de equipos para el segundo equipo de combate de Brigada Blindada del Ejército (ABCT).

- Compra de diez barcos de combate en el año fiscal 2019.

- Aumento de la producción del avión F-35 y el avión F/A-18.

- Mejoramiento de estrategia de disuasión mediante la modernización de la tríada nuclear1.

- Aumento de los fondos para mejorar las comunicaciones y la resiliencia en el espacio.

- Apoyo a las Fuerzas Armadas de los Estados Unidos con un aumento salarial de $2.6 \%$.

- Incremento en la innovación tecnológica para aumentar la letalidad.

La solicitud de presupuesto del Presidente para el año fiscal 2019 es de $\$ 686.1$ billones (Chief Financial Officer, 2018, pgs. 1-2). Este representa un crecimiento real del 5 por ciento sobre el presupuesto inicial del año fiscal 2018 y un crecimiento real del 10 por ciento con respecto a la Resolución Continua actual (RC). Si bien se evidencia una disminución de 7 años, el gasto en defensa se mantiene cerca de mínimos históricos como parte de la economía de los Estados Unidos como se observa a continuación: (ver figura 1)

Adicional a las iniciativas de la NSD, el Departamento de Defensa busca ser estratégicamente predecible, pero operativamente impredecible, disuadir o derrotar a los competidores estratégicos a largo plazo será su desafío, diferente a los adversarios regionales que fueron el centro de sus anteriores estrategias. Para conseguir esto el DoD expandirá el espacio competitivo mientras persigue tres líneas de esfuerzo: 1) fortalecer los programas de preparación militar a medida que se construye una Fuerza Conjunta más letal, 2) fortalecer las alianzas y atraer nuevos socios, 3) reformar las prácticas comerciales del Departamento para lograr un mayor rendimiento y asequibilidad. 


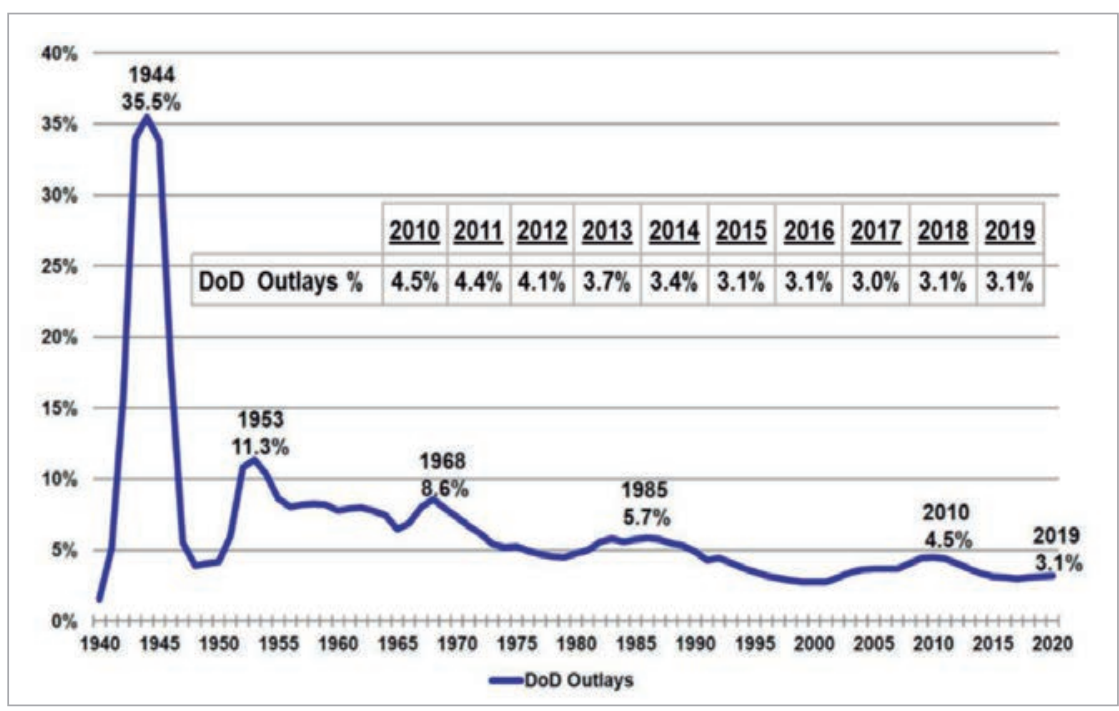

Figura 1. Desembolsos de Defensa vs. Producto Interno Bruto 1940 - 2023

Fuente: Defense Budget Overview - United States, Department of Defense/Fiscal Year 2019 budget request. P. 1

El presupuesto presentado por el Presidente Donald Trump en el año fiscal 2018 incluyó realmente $\$ 603$ mil millones en fondos discrecionales básicos para la defensa nacional, $\$ 64.6$ mil millones para operaciones de contingencia en el extranjero y $\$ 9.7$ mil millones en gastos obligatorios para una total de $\$ 677.1 \mathrm{mil}$ millones en fondos para la defensa nacional (incremento del $9.4 \%$ a la solicitud del último año de Barack Obama), conocidos como función de presupuesto 050 (Blakeley, 2017), estos dineros están destinados a alcanzar el equilibro del sector defensa, sin embargo, renunciar a una solicitud de gasto de defensa adicional en esta primera propuesta de presupuesto, cuando una nueva administración tiene la mayor posibilidad de hacer grandes correcciones fue un error estratégico. Al retrasar la solicitud de un aumento sustancial se ha dejado al Congreso como responsable para establecer los términos del debate sobre el presupuesto.

No obstante, es considerable la posición del Presidente Trump al incrementar el presupuesto de defensa que por tendencia venía en unos bajos históricos. Del presupuesto solicitado en fondos discrecionales (\$639.1 mil millones en 2018), $\$ 182.6$ mil millones (28.6\%) fueron asignados a la Fuerza Aérea, $\$ 179.6$ mil millones $(28.1 \%)$ a la Marina y la Infantería de Marina, $\$ 164.7$ mil millones (25.8\%) al Ejército y $\$ 112.3$ mil millones (17.4\%) al Departamento de Defensa (DoD) (Blakeley, 2017). 
Así mismo, es necesario revisar la asignación de recursos por categorías de apropiación de los fondos de defensa. Para el 2018 fueron asignados \$271 mil millones en fondos O\&M (operaciones y mantenimiento), \$146 mil millones para personal militar (MILPERS), \$124 mil millones para adquisiciones y \$83 mil millones para investigación, desarrollo, pruebas e ingeniería (RDT\&E).

Otra categoría para revisar dentro del presupuesto de defensa de los Estados Unidos son las Operaciones de Contingencia en el Extranjero (Overseas Contingency Operations - OCO), estas tuvieron una asignación en el 2018 de $\$ 65.8$ mil millones y se prevé un incremento del $23.2 \%$ para el 2019 (\$89 mil millones). Estas misiones se resumen en: Operation Fredoom's Sentinel (OFS), Operation Inherent Resolve (OIR), European Deterrence Initiative (EDI) y Cooperación en Seguridad con diferentes socios y aliados.

\subsection{Orientación futura, modernización de las fuerzas de defensa, adquisición de armas a gran escala, etc.}

El resurgimiento de la competencia estratégica a largo plazo y la rápida dispersión de las tecnologías y conceptos de guerra, han requerido una respuesta estructurada por parte de Estados Unidos; China y Rusia han reducido las ventajas militares y tecnológicas del DoD, exigiendo innovadoras formas de lucha, por esta razón se estipulan los siguientes objetivos de defensa (Department of Defense, 2018, p. 8):

- Defender a la patria de ataques.

- Mantener las ventajas militares de la Fuerza Conjunta (a nivel mundial y en regiones claves).

- Disuadir adversarios de la agresión contra los intereses vitales.

- Permitir que las contrapartes interagenciales de los Estados Unidos avancen en la influencia del país.

- Mantener el balance de poderes regionales favorables en la región indopacífico, Europa, Medio Oriente y hemisferio occidental.

- Defender a los aliados de la agresión militar y reforzar el apoyo de los socios contra la coacción, compartiendo de manera justa las responsabilidades en la defensa común.

- Persuadir, prevenir a los adversarios del Estado y a los actores no estatales de adquirir, proliferar o usar armas de destrucción masiva.

- Prevenir el accionar terrorista en operaciones externas contra Estados Unidos, sus ciudadanos, aliados y socios en el exterior.

- Asegurar que los dominios comunes permanezcan abiertos y libres. 
- Establecer una base de innovación de Seguridad Nacional incomparable, que apoye eficazmente las operaciones del Departamento de Defensa.

El Departamento de Defensa (DoD) es responsable de garantizar que la Fuerza Conjunta siga protegiendo simultáneamente a la patria estadounidense, responda y derrote a la agresión adversaria en el extranjero y lleve a cabo una campaña antiterrorista global en cooperación con aliados y socios de los Estados Unidos, con capacidad para responder a las amenazas emergentes. Por lo tanto, el programa de defensa debe ser capaz de abordar, tanto los requisitos a corto plazo de estos imperativos estratégicos, al tiempo que garantiza que las Fuerzas Armadas puedan prevalecer contra los desafíos futuros en estas áreas de misión. Para ello, cuenta con varios programas, como el de adquisición de armas que en total requiere para el año 2018 y 2019, más de 42 billones para su ejecución (Chief Financial Officer, 2018, p. 3).

Tabla No. 2. Principales programas de armas (presupuesto 2018 - 2019)

\begin{tabular}{|c|c|c|c|c|c|}
\hline \multirow{2}{*}{\multicolumn{2}{|c|}{$\begin{array}{c}\text { SISTEMAS DE ARMAS } \\
\text { Cantidad }\end{array}$}} & \multicolumn{2}{|c|}{ Año fiscal 2018} & \multicolumn{2}{|c|}{ Año fiscal 2019} \\
\hline & & $\begin{array}{c}\text { \$ en } \\
\text { billones }\end{array}$ & Cantidad & $\begin{array}{c}\text { \$ en } \\
\text { billones }\end{array}$ & \\
\hline \multicolumn{6}{|l|}{ Aeronaves } \\
\hline F-35 & Joint Strike Fighter & 70 & 10.8 & 77 & 10.7 \\
\hline $\mathrm{KC}-46 \mathrm{~A}$ & Tanker & 15 & 3.1 & 15 & 3.0 \\
\hline P-8A & Poseidon & 7 & 1.6 & 10 & 2.2 \\
\hline $\mathrm{F} / \mathrm{A}-18 \mathrm{E} / \mathrm{F}$ & Super Hornet & 14 & 1.3 & 24 & 2.0 \\
\hline $\mathrm{CH}-53 \mathrm{~K}$ & $\begin{array}{l}\text { King Stallion Heli- } \\
\text { copter }\end{array}$ & 4 & 1.1 & 8 & 1.6 \\
\hline E-2D AHE & Advanced Hawkeye & 5 & 1.1 & 4 & 1.2 \\
\hline AH-64E & Apache Helicopter & 63 & 1.4 & 60 & 1.3 \\
\hline UH-60 & $\begin{array}{l}\text { Black Hawk Heli- } \\
\text { copter }\end{array}$ & 48 & 1.1 & 68 & 1.4 \\
\hline $\mathrm{V}-22$ & Osprey & 6 & 0.9 & 7 & 1.3 \\
\hline MQ-4 & $\begin{array}{l}\text { Triton Unmanned } \\
\text { Aerial Vehicle }\end{array}$ & 3 & 0.9 & 3 & 0.9 \\
\hline \multicolumn{6}{|c|}{ Misiles de Defensa/Nucleares disuasivos } \\
\hline BMDS & $\begin{array}{l}\text { Ballistic Missile De- } \\
\text { fense System }\end{array}$ & - & 9.9 & - & 9.9 \\
\hline B-21 & Raider & - & 2.0 & - & 2.3 \\
\hline SSBN & $\begin{array}{l}\text { COLUMBIA Class } \\
\text { Submarine }\end{array}$ & - & 1.9 & - & 3.7 \\
\hline
\end{tabular}




\begin{tabular}{|c|c|c|c|c|c|}
\hline \multirow{2}{*}{\multicolumn{2}{|c|}{$\begin{array}{c}\text { SISTEMAS DE ARMAS } \\
\text { Cantidad }\end{array}$}} & \multicolumn{2}{|c|}{ Ańo fiscal 2018} & \multicolumn{2}{|c|}{ Año fiscal 2019} \\
\hline & & \multirow{2}{*}{$\begin{array}{c}\begin{array}{c}\text { \$ en } \\
\text { billones }\end{array} \\
-\end{array}$} & \multirow{2}{*}{$\begin{array}{c}\text { Cantidad } \\
1.3\end{array}$} & \multirow{2}{*}{$\begin{array}{c}\begin{array}{c}\text { \$ en } \\
\text { billones }\end{array} \\
-\end{array}$} & \multirow[b]{2}{*}{1.2} \\
\hline Trident II & $\begin{array}{l}\text { Trident II Missile } \\
\text { Mods }\end{array}$ & & & & \\
\hline LRSO & $\begin{array}{l}\text { Long Range Standoff } \\
\text { Weapon }\end{array}$ & - & 0.5 & - & 0.6 \\
\hline GBSD & $\begin{array}{l}\text { Ground Based Strate- } \\
\text { gic Deterrent }\end{array}$ & - & 0.2 & - & 0.3 \\
\hline B61 Tailkit & $\begin{array}{l}\text { B61 Mod } 12 \text { Life } \\
\text { Extension Program }\end{array}$ & 30 & 0.2 & 250 & 0.3 \\
\hline \multicolumn{6}{|l|}{ Barcos } \\
\hline SSN 774 & $\begin{array}{l}\text { VIRGINIA Class Sub- } \\
\text { marine }\end{array}$ & 2 & 5.5 & 2 & 7.4 \\
\hline DDG 51 & $\begin{array}{l}\text { ARLEIGH BURKE } \\
\text { Destroyer }\end{array}$ & 2 & 4.0 & 3 & 6.0 \\
\hline CVN 78 & FORD Aircraft Carrier & 1 & 4.6 & - & 1.8 \\
\hline LCS & Littoral Combat Ship & 2 & 1.7 & 1 & 1.3 \\
\hline T-AO & $\begin{array}{l}\text { Fleet Replenishment } \\
\text { Oiler }\end{array}$ & 1 & 0.5 & 2 & 1.1 \\
\hline ESB & Expeditionary Sea Base & - & - & 1 & 0.7 \\
\hline T-ATS & $\begin{array}{l}\text { Towing, Salvage, and } \\
\text { Rescue Ship }\end{array}$ & 1 & 0.1 & 1 & 0.1 \\
\hline \multicolumn{6}{|l|}{ Espacio } \\
\hline EELV & $\begin{array}{l}\text { Evolved Expendable } \\
\text { Launch Vehicle }\end{array}$ & 3 & 1.9 & 5 & 2.0 \\
\hline GPS & $\begin{array}{l}\text { Global Positioning } \\
\text { System }\end{array}$ & - & 1.1 & - & 1.5 \\
\hline SBIRS & $\begin{array}{l}\text { Space Based Infrared } \\
\text { System }\end{array}$ & - & 1.5 & - & 0.8 \\
\hline \multicolumn{6}{|c|}{ Sistemas de tierra } \\
\hline JLTV & $\begin{array}{l}\text { Joint Light Tactical } \\
\text { Vehicle }\end{array}$ & 2.777 & 1.1 & 5.113 & 2.0 \\
\hline
\end{tabular}

Fuente: Defense Budget Overview - United States, Department of Defense/Fiscal Year 2019 budget request. p. 3

Igualmente, existen otras iniciativas que buscan incrementar la capacidad militar de Estados Unidos, especialmente garantizar su liderazgo a nivel mundial, para ello continuará con la inversión en el poder aéreo, como se evidencia en la tabla anterior, pues es una prioridad la adquisición y mantenimiento de aviones de combate y bombarderos de la Armada y la Fuerza Aérea con una proyección al 2020, igualmente los programas de avance tecnológico y reducción del riesgo se 
incluyen en las capacidades de dominación aérea (Chief Financial Officer, 2018, ps. 3-4).

Por su parte, el poder marítimo se focaliza en los portaaviones nucleares y buques de guerra anfibios que apoyarán las misiones de control del mar y proyección de potencia, proporcionando una mayor detección a largo alcance y la capacidad aire - superficie - misil balístico. Igualmente, el presupuesto solicitado respalda la adquisición de capacidades logísticas (nave de combate litoral y AO205), que proporcionan combustible y apoyo logístico a los buques desplegados asegurando presencia continua. Por su parte, los submarinos armados de misiles tácticos se empezarán a desmantelar en el año 2020 para asegurar la implementación de los Virginia Payload Module y Block V Virginia Class Submarines que reemplazarán en gran parte esta capacidad. Por último, el poder marítimo también incluye inversión en programas de guerra electrónica superficial como una capacidad defensiva marítima. El presupuesto al año 2019 seguirá financiando el programa de 125 misiles estándar (SM-6) por año, proporcionando largo alcance a la flota desplegada, también financiará la adquisición de misiles antibuque de largo alcance (LRASM) para la Armada y la Fuerza Aérea (Chief Financial Officer, 2018, ps. 3-5).

En cuanto a las municiones, Estados Unidos tiene aún operaciones militares en varios lugares del mundo, definir el tipo y cantidad de las mismas es el mayor desafío en esta materia, con el fin de reabastecer la lucha desde tierra, mar o aire. Las más usadas son municiones guiadas de bajo daño colateral que se utilizan por más de un servicio militar y por los aliados estadounidenses. Su mayor gasto ha sido en la lucha contra el terrorismo, actualmente Irak y Siria (ISIS). Se debe recordar que el sistema de producción y/o adquisición de municiones (base industrial orgánica y comercial) ayuda en la capacidad de contar con una fuerza más letal (Chief Financial Officer, 2018, ps. 3-7).

En lo referente a la modernización y disuasión nuclear, esta se ha convertido en la prioridad del Departamento de Defensa, recapitalizar los sistemas de entrega nuclear y los sistemas de apoyo asociados requerirán un aumento en el gasto en los próximos 20 años. La mayoría de sistemas de disuasión nuclear cumplirá su vida útil durante 2025 - 2035, por lo tanto, los programas de reemplazo garantizarán la capacidad de Estados Unidos. Por ejemplo, el sistema de misiles de disuasión estratégica basados en tierra (GBSD) reemplazará a los Minuteman III en el 2028. El misil de largo alcance (LRSO) reemplazará el misil de crucero AGM-868 Air que ha estado en funcionamiento desde 1986. El submarino de misiles balísticos Class Columbia (SSBN) reemplazaría el OHIO-Class a principios del 2030. Por su parte, el proyecto de Trident II (D5) pretende alargar la vida útil del misil D5LE. 
El bombardero estratégico B-21 que representa la conjunción entre el poder aéreo convencional y el poder nuclear, desarrollará nuevas tecnologías para lograr un mayor alcance. Los nuevos aviones F35A reemplazarían en el 2025 el actual F15 de la Fuerza Aérea y el F16DCA para soportar una disuasión extendida. Finalmente, la bomba de gravedad nuclear B61 Mod 12, entrará en un proyecto de modernización que permita incrementar su vida útil mientras se hace más segura y confiable. Esta última iniciativa se realiza en conjunto con el Departamento de Energía de Estados Unidos.

En la iniciativa de Defensa Antimisiles se incluye la solicitud de un presupuesto por 12.9 mil millones, incluyendo 9.9 mil millones para la Agencia de Defensa Antimisiles (MDA), la cual pretende desarrollar un campo adicional de misiles en Alaska, implementar interceptores terrestres (GBI) acerca de 64 misiles a partir del año 2023 y dotar la infraestructura para mantener una flota operativa en el futuro. Así mismo, incluye un sistema de radares, uno de largo alcance en Alaska, uno de defensa en Hawái y uno de discriminación de mediano alcance en el Pacífico. Es fundamental señalar que Estados Unidos busca construir sistemas de defensa regional de manera interoperables con sus socios y aliados para misiles balísticos de corto alcance (SRBM), de mediano alcance (MRBM) y de alcance intermedio (IRBM). Igualmente, con el presupuesto solicitado busca apoyar a las fuerzas militares de Corea del Sur (USFK) para mejorar su capacidad en la península, financiar la Terminal de Defensa Aérea de Altitud Alta (THAAD) y continuar con los programas de cooperación con Israel (Iron Dome system to defeat shortrange missile ando rockets, David's Sling Weapon System y Arrow-3 system) (Chief Financial Officer, 2018, ps. 3-10).

Todo lo anterior se suma a los proyectos de investigación, innovación, ciencia y tecnología que Estados Unidos promueve a través del fortalecimiento de su base industrial militar y las orientaciones del gobierno nacional, por ejemplo, se ha solicitado también presupuesto que fortalezca la preparación y ejecución de operaciones en el ciberespacio a través de 133 equipos2 de Fuerza Cibernética (CMF). Por su parte cada Fuerza Armada, ha presentado sus necesidades específicas, es el caso del Ejército, que requiere ser una fuerza más amplia, moderna y letal para derrotar amenazas regionales y globales. La Armada buscará reducir el atraso en los procesos de mantenimiento a largo plazo para garantizar el empleo de su flota. El Cuerpo de Marines priorizará la modernización al mismo tiempo que hace inversiones clave para estructurar sus líneas de fuerza en la Infantería de Marina al 2025. Y finalmente, la Fuerza Aérea se focalizará en la preparación y capacitación operacional, su infraestructura, dotación y mejoramiento y modernización de armas. 


\subsection{Estructura militar de la defensa}

En procura de la defensa de sus intereses, Estados Unidos ha organizado su estructura militar bajo el liderazgo del Departamento de Defensa (DoD), el Secretario de Defensa, actualmente James N. Mattis, es el principal asesor de la política de defensa del Presidente y bajo su dirección están los Departamentos Militares y los Comandos Unificados, así como el Estado Mayor Conjunto (Joint Chiefs of Staff - JCS), la oficina del Secretario (Office of the Secretary of Defense) conformada por asesores de alto nivel que planean, formulan y ejecutan las políticas de seguridad de la nación en las siguientes áreas: política, finanzas, preparación para la fuerza y compras, básicamente, administran ideas, dinero, personas y material; las Agencias de Defensa y el Departamento de Actividades de Campo de Defensa y demás oficinas, agencias, actividades, organizaciones y comandos establecidos por ley o designados por el Presidente.

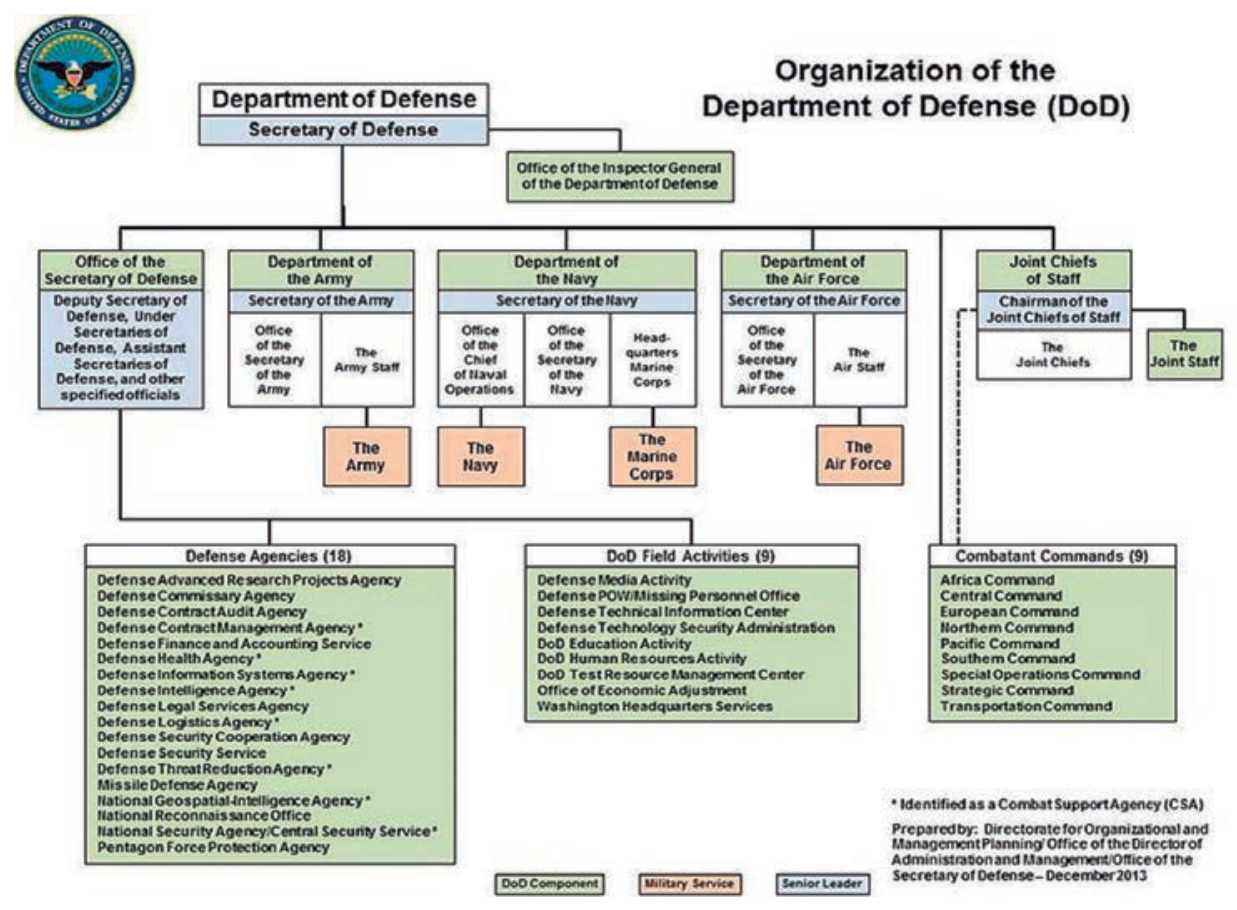

Figura 2: Estructura del Departamento de Defensa (DoD) Fuente: Department of Defense - Chief Management Officer

Actualmente, el personal que integra las Fuerzas Armadas estadounidenses son 1.33 millones, distribuidos en 467.569 de Ejército, 322.899 de la Armada 
(Navy), 317.928 de la Fuerza Aérea, 184.123 del Cuerpo de Marines y 40.721 de la Guardia Costera (BBC Mundo, 2017). Para el 2019, se espera un incremento en las Fuerzas de un 24\%, completando 1.38 millones de integrantes.

Los Departamentos Militares tienen como propósito, capacitar y equipar a su personal para realizar tareas de combate de guerra, mantenimiento de la paz, asistencia humanitaria y asistencia por desastre. Los Departamentos Militares son:

\section{Ejército (United States Army):}

Defiende el territorio de los Estados Unidos, sus mancomunidades y posesiones. Opera en más de 50 países. Lo componen un elemento activo y un elemento de reserva y lleva a cabo misiones operativas e institucionales.

El Ejército de los Estados Unidos tiene dos componentes: activo y de reserva (reserva del Ejército y la Guardia Nacional del Ejército). Independientemente del componente, el Ejército lleva a cabo misiones tanto operativas como institucionales. El Ejército operativo es el despliegue de cuerpos, divisiones, brigadas y batallones que realizan misiones militares en todo el mundo, por su parte, el Ejército institucional proporciona apoyo al Ejército operativo y hace referencia a las instituciones que ofrecen infraestructura, entrenamiento, equipo, base industrial, despliegue, preparación y logística necesaria para apoyar a todos los miembros de la fuerza. Su actual estructura comprende (U.S. Army, 2018):

1. Estructura del Comando del Ejército (Army Commands - ACOM)

a. Comando de las Fuerzas Armadas de los Estados Unidos (U.S. Army Forces Command - FORSCOM): entrena, moviliza, despliega, sostiene, transforma y reconstruye las fuerzas convencionales asignadas, proporcionando el poder terrestre y el apoyo a los comandos combatientes.

b. Comando de Entrenamiento y Doctrina del Ejército (U.S. Army Training and Doctrine Command - TRADOC): recluta, entrena y educa a los soldados del Ejército, apoya el entrenamiento en las unidades, actualiza y emite la doctrina, establece estándares y construye el futuro del Ejército.

c. Comando de Material del Ejército (U.S. Army Materiel Command - AMC): proporciona tecnología superior, soporte a la adquisición y logística, garantizando la capacidad de la fuerza de tierra dominante en Estados Unidos y países aliados. 
2. Comandos del componente del servicio del Ejército (Army Services Component Commands - ASCC)
a. US Army Africa (ASARAF)
b. US Army Central (USARCENT)
c. US Army North (USARNORTH)
d. US Army South (USARSO)
e. US Army Europe (USAREUR)
f. US Army Pacific (USARPAC)
g. US Army Special Operations Command (USASOC)
h. Military Surface Deployment and Distribution Command (SDDC)
i. US Army Space and Missile Defense Command/Army Forces Strategic Command (USASMDC/ARSTRAT)
j. US Army Cyber Command (USARCYBER)

3. Unidades de Reporte Directo (Direct Reporting Units - DRU)
a. US Army Medical Command (MEDCOM)
b. US Army Intelligence and Security Command (INSCOM)
c. US Army Criminal Investigation Command (USACIDC)
d. US Army Human Resources Command (HRC)
e. US Army Corps of Engineers (USACE)
f. US Army Military District of Washington (MDW)
g. US Army Test and Evaluation Command (ATEC)
h. US Military Academy (USMA)
i. US Army Acquisition Support Center (USAASC)
j. US Army Installation Management Command (IMCOM)
k. US Army War College
1. Arlington National Cemetery
m. US Army Accessions Support Brigade

\section{Armada (United States Navy):}

Mantiene, entrena y equipa las fuerzas marítimas listas para el combate, capaces de ganar guerras, disuadir la agresión y mantener la libertad de los mares. Brinda una respuesta rápida a las crisis en todo el mundo e impide las mayores agresiones debido a la ubicación de portaaviones en puntos de acceso como el Lejano Oriente, Golfo Pérsico y Mar Mediterráneo.

La estructura de la Armada de los Estados Unidos consta de cuatro órganos principales: la Oficina del Secretario de la Marina, la Oficina del Jefe 
de Operaciones Navales, las fuerzas operativas y el Cuerpo de Guardacostas (Department of the Navy).

Las fuerzas operativas son:

1. United States Fleet Forces Command

a. Submarine Force US Atlantic Fleet

b. Surface Forces Atlantic

c. Naval Air Forces Atlantic

d. Task Force 20 (TF20): opera en el océano Atlántico desde el Polo Norte hasta el Polo Sur. Proporciona entrenamiento de fuerza y ejercicios marítimos a la vez que apoya las misiones de servicio en operaciones combinadas en el mar.

e. Military Sealift Command (MSC): portador de material marítimo.

f. Navy Expeditionary Combat Command (NECC)

2. United States Pacific Fleet
a. Submarine Forces Pacific
b. Surface Force Pacific
c. Naval Air Forces Pacific
d. Third Fleet (desplegada en el Océano Pacífico Norte, Sur y Este junto con la Costa Oeste de los Estados Unidos).
e. Seventh Fleet (desplegada en el Pacífico Occidental y el Océano Índico, extendiéndose hasta el Golfo Pérsico y abarcando gran parte de la costa este de África).
f. Naval shore commands: Commander Naval Force Korea (CNFK), Commander Naval Forces Marianas (CNFM) and Commander Naval Forces Japan (CNFJ).

3. United States Naval Forces Central Command
a. Fifth Fleet (su área de responsabilidad es Medio Oriente, inclu- yendo el Golfo Pérsico, el Mar Rojo, el Golfo de Omán y partes del Océano Índico).
b. Combined Task Force 150

4. United States Naval Forces Southern Command
a. Fourth Fleet (realiza actividades de interdicción marítima militar para contrarrestar el narcoterrorismo y actividades de cooperación en seguridad, así como asistencia humanitaria. Lo anterior en la misma jurisdicción del Comando Sur de los Estados Unidos).
b. US Naval Forces Southern Command's (USNAVSO) 
5. United States Naval Forces Europe

a. Sixth Fleet (desplegada en el Mar Mediterráneo y el Mar Negro, con sede en Nápoles, Italia). Esta Flota apoya las operaciones de la OTAN.

6. United States Fleet Cyber Command

a. Tenth Fleet (operaciones en los dominios marítimos, ciberespacio y de la información. Tiene el control operacional de las fuerzas cibernéticas de la Marina, como un subcomponente del Comando Cibernético de los Estados Unidos).

7. United States Navy Reserve

8. United States Naval Special Warfare Command

a. Actúa como el componente naval del Comando de Operaciones Especiales y proporciona visión, liderazgo, orientación doctrinal, recursos para operaciones especiales. Incluye 2.450 componentes de SEAL y 600 tripulantes de combate para Guerra Especial.

9. Operational Test and Evaluation Force

Como se menciona existen seis flotas numeradas activas y otras varias que actualmente no lo están. La primera flota $(1 \mathrm{~F})$ está inactiva y pertenece a la flota del Pacífico, la segunda flota (2F) está inactiva y pertenece a la flota del Atlántico, la tercera flota (3F) está activa y pertenece a la Flota del Pacífico, la cuarta flota (4F) está activa y pertenece al Comando Sur de las Fuerzas Navales, la quinta flota (5F) está activa y pertenece al Comando Central de las Fuerzas Navales, la sexta flota (6F) está activa y pertenece a las Fuerzas Navales en Europa, la séptima flota (7F) está activa y pertenece a la Flota del Pacífico, la octava flota (8F) está inactiva y pertenece a la Flota del Atlántico, la novena flota (9F) está inactiva y pertenece a las Flotas Atlántico y Pacífico, la décima flota (10F) está activa y pertenece al Comando Cibernético, la décimo primera flota $(11 \mathrm{~F})$ está inactiva y pertenece a las Flotas Atlántico y Pacífico, y por último, la flota décimo segunda (12F) está inactiva y pertenece a las Fuerzas Navales en Europa. (Ver figura 3).

Finalmente, existen los siguientes comandos que pertenecen directamente a la Oficina del Jefe de Operaciones Navales y proporciona apoyo a las fuerzas operativas en forma de: instalaciones para la reparación de maquinaria y electrónica, centros de comunicaciones, áreas de entrenamiento y simuladores, reparación de 


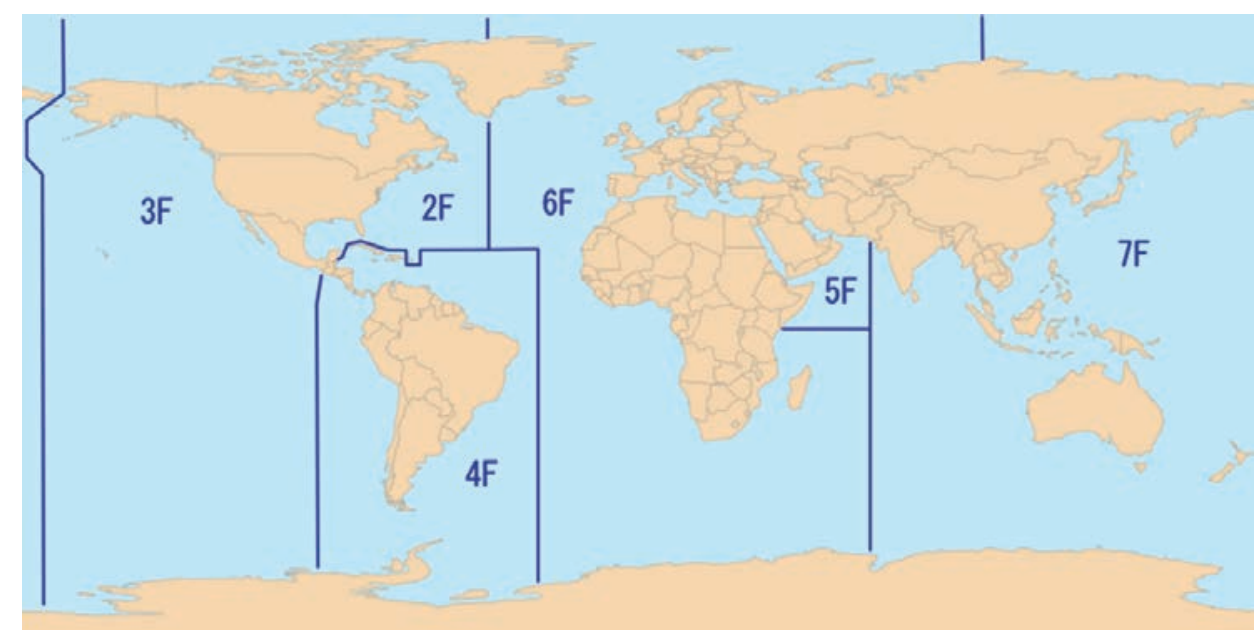

Figura 3: Áreas de responsabilidad de las Flotas activas de Estados Unidos Fuente: Department of Navy

barcos y aeronaves, inteligencia y apoyo meteorológico, áreas de almacenamiento para piezas en reparación, combustibles y municiones; instalaciones médicas y dentales y bases aéreas. Estos son:

1. Naval Sea Systems Command

2. Naval Air Systems Command

3. Naval Facilities Engineering Command

4. Naval Supply Systems Command

5. Space and Naval Warfare Systems Command

6. Strategic Systems Programs

7. United States Naval Academy

8. Naval Education and Training Command

9. Naval Meteorology and Oceanography Command

10. Office of Naval Intelligence

11. Naval Strike and Air Warfare Center

12. Naval Security Group

13. Naval Legal Service Command

14. United States Naval Observatory

15. Naval Safety Center

\section{Cuerpo de Marines (United States Marine Corps):}

Es un componente del Departamento de Armada. El cuerpo de Marines de los ESTADOS UNIDOS mantiene fuerzas expedicionarias listas, unidades de aire- 
tierra integradas y basadas en el mar para operaciones de contingencia y combate, y los medios para estabilizar o contener disturbios internacionales.

El Cuerpo de Marines cuenta con dos mandos principales: Marine Forces Pacific (cuartel general en Pearl Harbor, Hawái) y el Marine Forces Atlantic (base en Norfolk, Virginia). Para su despliegue cuenta con Marine Air-Ground Task Force (MAGFT) conformada por 3 Marine Expeditionary Force (MEF - división, ala aérea o cuerpo logístico) y 7 Marine Expeditionary Unit (MEU - batallones de infantería de marina reforzados y escuadrones compuestos).

\section{Guardacostas (United States National Guard):}

Brinda los servicios de seguridad marítima y legal, protección marina y ambiental y apoyo naval militar. Ofrece apoyo marítimo único y crítico, patrullando nuestras costas, realizando operaciones de rescate de emergencia, conteniendo y limpiando derrames de petróleo y evitando que millones de dólares en drogas ilegales inunden a las comunidades estadounidenses. El Cuerpo de Guardacostas está organizado de la siguiente manera (United States Coast Guard):

1. Área Atlántica

a. Distrito 1 (norte de Nueva Jersey, Nueva York, Connecticut, Rhode Island, Massachusetts, New Hampshire, Vermont y Maine).

b. Distrito 5 (desde Carolina del Sur hasta Nueva Jersey).

c. Distrito 7 (área de 1.7 millones de millas cuadradas incluyendo Puerto Rico, Florida, Georgia, Carolina del Sur).

d. Distrito 8 (26 estados incluidos Texas, Louisiana, Mississippi, Alabama y la península de Florida).

e. Distrito 9 (responsable de las actividades de la Guardia Costera a lo largo de los cinco Grandes Lagos, la vía marítima de San Lorenzo y partes de los estados circundantes, incluyendo 6.700 millas de costa y 1.500 millas de la frontera internacional con Canadá).

2. Área Pacífica

a. Distrito 11 (California, Nevada, Utah y Arizona).

b. Distrito 13 (Washington, Oregon, Idaho y Montana).

c. Distrito 14 (islas de Hawái, Guam, Samoa Americana y actividades en Saipan, Singapur y Japón).

d. Distrito 17 (es responsable de la región marítima de Alaska que abarca más de 3.853.500 millas cuadradas y más de 47.300 millas de costa en Alaska y el Ártico). 
3. Comando de Apoyo a la Misión (DCMS)
a. Recursos Humanos
b. Ingeniería y logística
c. Tecnología e información
d. Adquisiciones
e. Director de Operaciones Logísticas
f. Comando de preparación de Fuerza
g. Academia de la Guardia Costera
h. Integración de soportes de misión
i. Política de Seguridad y Gestión

4. Comando de Operaciones (DCO)
a. Política de respuesta
b. Política de prevención
c. Capacidad
d. Cyber Command
e. Centro de Comando Nacional
f. Centro Global de Coordinación (MOTR)
g. Dirección de Gestión de Recursos
h. Dirección de Asuntos Internacionales y Política Exterior

5. Reportes Directos
a. Asuntos públicos
b. Recursos - Presupuesto
c. Derechos civiles
d. Asuntos jurídicos

\section{Fuerza Aérea (United States Air Force):}

Proporciona una capacidad aérea y espacial rápida, flexible y, cuando es necesario, letal, enviando fuerzas a cualquier parte del mundo en menos de 48 horas. Participa en misiones de evacuación de mantenimiento de paz, humanitarias y aeromédicas. Actualmente, su organización es la siguiente (US Air Force):

1. Cuartel General

2. Air Combat Command (ACC)
a. Centro de Guerra (USAFWC)
b. 1a Fuerza Aérea
c. 9a Fuerza Aérea
d. 12a Fuerza Aérea 
3. Air Education and Training Command (AETC)
a. 2a Fuerza Aérea
b. $19^{a}$ Fuerza Aérea
c. Servicio de Reclutamiento de la Fuerza Aérea
d. Universidad del Aire
e. Centro Médico Wilford Hall

4. Air Force Global Strike Command (AFGSC)
a. $8^{a}$ Fuerza Aérea
b. 20a Fuerza Aérea

5. Air Force Materiel Command (AFMC)
a. Centro de Sistemas Aeronáuticos
b. Centro de Pruebas en Vuelo
c. Centro de Soporte Global y Logística de la Fuerza Aérea
d. Centro de Armas Nucleares de la Fuerza Aérea
e. Laboratorio de Investigación
f. Centro de Asistencia de Seguridad
g. Centro de Armamento Aéreo
h. Centro Arnold de Desarrollo e Ingeniería
i. Centro de Sistemas Electrónicos

6. Air Force Reserve Command (AFRC)
a. 4a Fuerza Aérea
b. $10^{a}$ Fuerza Aérea
c. 22a Fuerza Aérea
d. Centro de Personal de la Reserva Aérea

7. Air Force Space Command (AFSPC)
a. $14^{a}$ Fuerza Aérea
b. 24a Fuerza Aérea
c. Centro Espacial de Sistemas y Misiles
d. Centro de Innovación y Desarrollo Espacial

8. Air Force Special Operations Command (AFSOC)
a. $23^{\text {a }}$ Fuerza Aérea
b. Centro de Entrenamiento de Operaciones Especiales de la Fuerza Aérea de ESTADOS UNIDOS

9. Air Mobility Command (AMC)
a. $18^{a}$ Fuerza Aérea
b. Centro Expedicionario de la Fuerza Aérea 
10. United States Air Forces in Europe (USAFE)
a. $\quad 3$ Fuerza Aérea (Alemania)
b. $17^{\text {a }}$ Fuerza Aérea (Alemania)

11. Pacific Air Forces (PACAF)
a. $\quad 5^{a}$ Fuerza Aérea (Japón)
b. $\quad 7^{\text {a }}$ Fuerza Aérea (Corea del Sur)
c. 11 a Fuerza Aérea (Alaska)
d. 13 a Fuerza Aérea (Hawái)

\section{Guardia Nacional (United States National Guard):}

Sus lazos personales con las comunidades locales son el complemento perfecto para el cumplimiento de misiones emergentes, sirven a la comunidad y al país, siendo una fuerza versátil, capaz de proporcionar apoyo en misiones de combate, emergencias domésticas, esfuerzos humanitarios, operaciones de seguridad nacional, entre otras, además de ser el apoyo militar durante la guerra (National Guard).

Esta Fuerza de Reserva está constituida por voluntarios y cada Estado de los ESTADOS UNIDOS tiene su propia Guardia Nacional, siendo el Gobernador su Comandante en Jefe y nombrando un Adjutant General quien será el máximo jefe de la Guardia en cada Estado.

Así mismo, las Fuerzas Militares de Estados Unidos están desplegadas a nivel mundial a través de los Comandos Unificados, seis comandantes tienes responsabilidades geográficas (USAFRICOM - USCENTCOM - USEUCOM USNORTHCOM - USPACOM - USSOUTHCOM) y tres comandantes tienen responsabilidades mundiales (USSOCOM-USSTRATCOM - USTRANSCOM). El DoD ejerce su autoridad para desplegar tropas y poder militar con el asesoramiento del Jefe del Estado Mayor Conjunto, cargo que desempeña el General del Cuerpo de Marines, Joe Dunford desde octubre de 2015. Los Comandos Unificados tienen las siguientes misiones y responsabilidades geográficas:

\section{Comando de los Estados Unidos en África (United States Africa Command - USAFRICOM) Sede: Kelley Barracks - Stuttgart, Alemania}

Es responsable de las relaciones militares con las naciones africanas, la Unión Africana y las organizaciones africanas de seguridad regional. Protege y defiende los intereses de los Estados Unidos mediante el fortalecimiento de las capacidades de defensa de las naciones africanas y, en cooperación con los gobiernos africanos, lleva a cabo misiones miliares que aumentan la seguridad, disuadiendo y derrotando las amenazas trasnacionales. 


\section{Comando Central de los Estados Unidos (United States Central Command - USCENTCOM) Sede: Base Aérea MacDill, Florida}

Es responsable de las operaciones en 20 países que se encuentran en el área central del globo: Afganistán, Bahrein, Egipto, Irán, Iraq, Jordania, Kazajstán, Kuwait, Kirguistán, Líbano, Omán, Pakistán, Qatar, Arabia Saudita, Siria, Tayikistán, Turkmenistán, Emiratos Árabes Unidos, Uzbekistán y Yemen. Utiliza alianzas nacionales e internacionales para desarrollar la cooperación entre las nacionales, responder a crisis, vencer las amenazas y apoyar el desarrollo de la región, lo que contribuye a su estabilidad.

Comando de los Estados Unidos en Europa (United States European Command - USEUCOM) Sede: Patch Barracks - Stuttgart, Alemania

Trabaja con la OTAN y otras naciones asociadas para abordar las necesidades de seguridad y defensa de las naciones de Europa y partes de Medio Oriente y Eurasia. USEUCOM coordina con estas naciones para encontrar soluciones de cooperación tanto en tiempo de paz como de guerra, para planificar misiones de capacitación, proporcionar asistencia humanitaria y desarrollar estrategias para promover la paz y la estabilidad en la región.

\section{Comando Norte de los Estados Unidos (United States Northern Command - USNORTHCOM) Sede: Base Aérea Peterson, Colorado}

Opera en el área de responsabilidad que abarca los Estados Unidos continentales: Alaska, México, Canadá, partes del Caribe y aguas circundantes. NORTHCOM es principalmente responsable del apoyo civil y la seguridad nacional, también supervisa el Comando de Defensa Aeroespacial de América del Norte (NORAD). Tiene pocas fuerzas permanentes, sin embargo, el Secretario de Defensa o el Presidente le asignan algunas cuando sea necesario para la ejecución de sus misiones.

Comando del Pacífico de los Estados Unidos (United States Pacific Command - USPACOM) Sede: Campamento H. M. Smith - Hawái

Supervisa un área de responsabilidad que se extiende desde las aguas de la costa oeste de los Estados Unidos hasta la frontera occidental de la India y desde la Antártida hasta el Polo Norte, abarcando 36 naciones diferentes. USPACOM y sus socios trabajan para promover el desarrollo de la región mientras cooperan para mejorar la seguridad, disuadir la agresión, responder con fuerza cuando sea necesario y proporcionar asistencia humanitaria. 


\section{Comando Sur de los Estados Unidos (United States Southern Command - USSOUTHCOM) Sede: Miami, Florida}

Supervisa un área de responsabilidad que abarca 31 naciones en América Latina al sur de México, América Central, América del Sur y el Mar Caribe. Trabaja para aumentar la seguridad de los Estados Unidos al comprometer a sus socios para mejorar las capacidades de mantenimiento de la paz de la región, promover los derechos humanos, disuadir las actividades ilegales asociadas con el tráfico ilícito y realizar ejercicios militares multinacionales diseñados para fortalecer las alianzas mientras desarrollan capacidades colectivas.

Estos Comandos Unificados con responsabilidades geográficas están compuestos por fuerzas de al menos dos Departamentos Militares y cumplen misiones amplias y continuas, principalmente, proporcionan un control efectivo sobre un área de responsabilidad que obedece al Plan de Comando Unificado (UCP), aprobado por el Presidente y que establece los principios básicos y orientaciones para los Comandantes Combatientes. Estos Comandos Unificados contribuyen efectivamente en el terrero a la materialización de la política exterior estadounidense, incrementando su liderazgo en los programas de asistencia y entrenamiento de ejército extranjeros (Withers, Isacson, Haugaard, Olson \& Fyke, 2008).

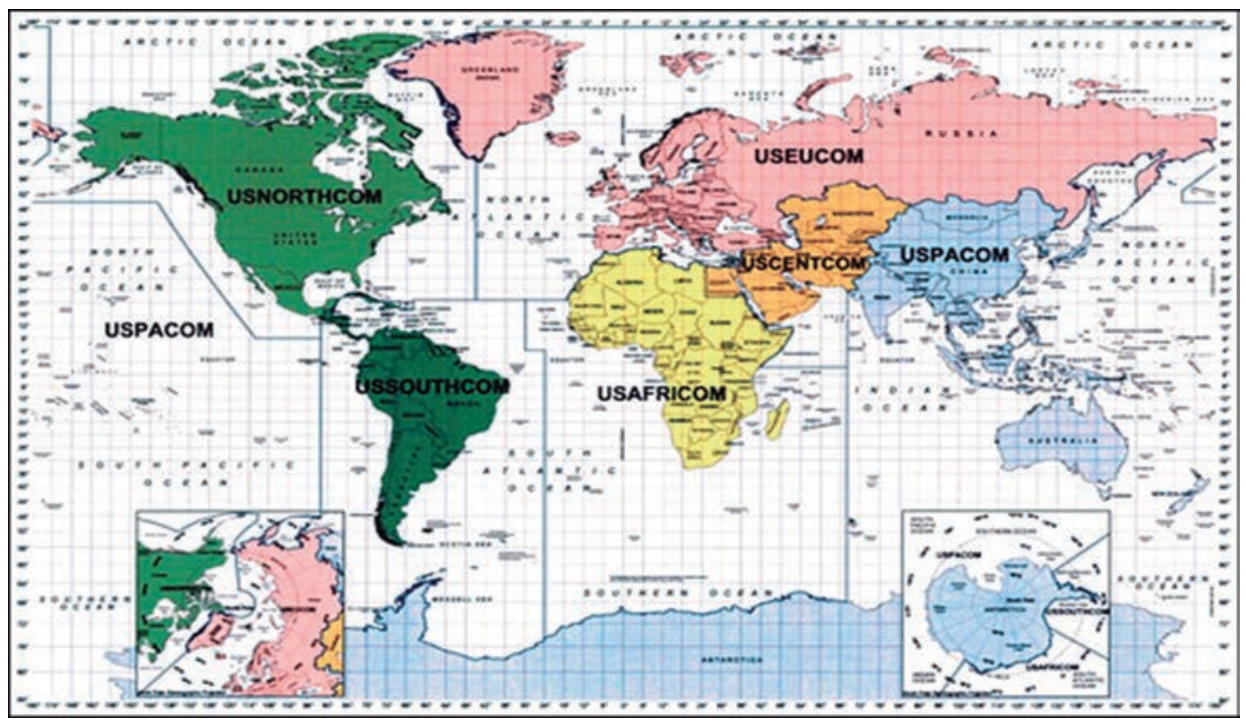

Figura 4: Áreas de responsabilidad de los Comandos Fuente: Department of Defense

Es preciso recordar que existen tres Comandos Unificados que tienen misiones estratégicas/funcionales a nivel mundial y brindan soporte a los Comandos Geográficos y a las Fuerzas en el territorio propio, los cuales son: 


\section{Comando de Operaciones Especiales de los Estados Unidos (United States Special Operations Command - USSOCOM) Sede: Base Aérea MacDill, Florida}

Es responsable de la planificación y realización de operaciones especiales. Ofrece acción directa en forma de ataques de corta duración y ofensivas a pequeña escala, reconocimiento especial, guerra no convencional, defensa interna extranjera, operaciones de asuntos civiles, contraterrorismo, operaciones psicológicas, operaciones de información, contra proliferación de armas de destrucción masiva, asistencia, operaciones de contrainsurgencia y cualquier actividad específica dirigida por el Presidente o el Secretario de Defensa.

Comando Estratégico de los Estados Unidos (United States Strategic Command - USSTRATCOM) Sede: Base Aérea Offutt, Nebraska

Tiene su sede en la Base de la Fuerza Aérea Offutt en Omaha, Nebraska. Lleva a cabo operaciones globales en asociación con otros Comandos Combatientes, servicios y agencias gubernamentales de los Estados Unidos para disuadir y detectar ataques estratégicos contra los Estados Unidos. El USSTRATCOM es responsable del mando de las capacidades nucleares de Estados Unidos, las operaciones espaciales, la vigilancia y el reconocimiento mundial, la inteligencia, las comunicaciones, las computadoras, la defensa antimisiles y el combate a las armas de destrucción en masa.

\section{Comando de transporte de los Estados Unidos (United States Transportation} Command - USTRANSCOM) Sede: Base Aérea Scott, Illinois

Proporciona al Departamento de Defensa un agregado de capacidades y activos de transporte. Junto con las asociaciones comerciales, USTRANSCOM permite una amplia gama de misiones conjuntas de movilidad.

Finalmente, se encuentran las Agencias de Defensa que están bajo la supervisión de la Oficina del Secretario de Defensa y son:

- Instituto de Investigación de Radiobiología de las Fuerzas Armadas (AFRRI)

- Agencia de Proyectos de Investigación Avanzados de la Defensa (DARPA)

- Agencia de Intendencia de Defensa (DeCA)

- Agencia de Contratos de Auditoría de la Defensa (DCAA)

- Agencia de Gestión de Contratos de la Defensa (DCMA)

- Servicio de Contabilidad y Finanzas de Defensa (DFAS) 
- Agencia de Sistemas de la Información de Defensa (DISA)

- Agencia de Servicios Legales de Defensa

- Agencia de Logística de Defensa (DLA)

- Agencia de Cooperación en Seguridad de Defensa (DSCA) (anteriormente conocida como Agencia de Asistencia en Seguridad de Defensa)

- Servicio de Seguridad de Defensa (DSS) (anteriormente conocida como Servicio de Investigación de Defensa)

- Centro de Información Técnica de Defensa (DTIC)

- Agencias de Reducción de Amenazas de la Defensa (DTRA)

- Agencia de Defensa de Misiles (MDA)

Por otro lado, Estados Unidos cuenta con todo un sistema que orienta los servicios de inteligencia no solo para la seguridad y defensa del país. Existen diversas agencias de defensa que son miembros de la Comunidad de Inteligencia de los Estados Unidos (United States Intelligence Community - IC) y operan bajo la jurisdicción del DoD, pero que simultáneamente actúan bajo lineamientos del Director de la Inteligencia Nacional, sirviendo como agencias de apoyo en combate, sin embargo, también asisten a los servicios responsables de la aplicación de la ley como la Agencia Central de Inteligencia (Central Intelligence Agency - CIA) y la Oficina Federal de Investigación (Federal Bureau of Investigation - FBI). Estas agencias son:

- Agencia de Inteligencia de la Defensa

- Agencia de Seguridad Nacional

- Agencia Nacional de Inteligencia - Geoespacial

- Oficina Nacional de Reconocimiento

\section{Capacidades de seguridad y defensa para el desarrollo}

Como se ha mencionado en el desarrollo del presente documento, es un objetivo de la actual Estrategia de Seguridad Nacional (NSS), el fortalecimiento de las alianzas de Estados Unidos y la construcción de nuevas asociaciones, para ella se ha creado una estrategia interagencial que trabaja con el Departamento de Estado y otras partes interesadas para brindar apoyo, asistencia y cooperación internacional, a través de relaciones bilaterales, regionales y globales que produzcan resultados estratégicos y operacionales beneficiosos para Estados Unidos, a través de una amplia gama de programas y actividades que permitan la interoperabilidad y la 
preparación, tanto en términos de capacidad, como en provisión de artículos y servicios de defensa, construcción de capacidad institucional, ejercicios y eventos de entrenamiento, intercambios militares, educación y formación en centros estadounidenses y la asociación para desarrollar capacidades tecnológicas clave (Chief Financial Officer, 2018, p. 9). Para lo anterior, Estados Unidos se concentra en tres elementos básicos:

- Mantener una base de respeto mutuo, responsabilidad, corresponsabilidad y prioridades.

- Expandir mecanismos consultivos regionales y todas aquellas herramientas de planificación colaborativa.

- Profundizar la interoperabilidad.

Se buscan alianzas y coaliciones, respaldadas por las redes de seguridad de nuevos socios en diferentes regiones de la siguiente manera (Department of Defense, 2018, p. 12):

- Ampliar las alianzas y asociaciones en la región Indo-Pacífica: busca crear una región libre y abierta, pero adicionalmente, que sea capaz de detener la agresión, mantener la estabilidad y garantizar el acceso libre a dominios comunes.

- Fortalecer la Alianza Transatlántica de la OTAN: como estrategia para detener a Rusia y el terrorismo. Al mismo tiempo, que reforzará el compromiso de los integrantes en la toma de decisiones, su capacidad de respuesta y la modernización de la alianza en el marco de una seguridad compartida.

- Fomentar coaliciones perdurables en Medio Oriente: el objetivo es negar la oportunidad de refugio a terroristas, así como el acceso de Estados Unidos a mercados de energía y rutas comerciales.

- Reforzar las ventajas en el Hemisferio Occidental: manteniendo su posición como líder interinstitucional. Estados Unidos profundizará sus relaciones con países de la región que aportan capacidades militares y comparten desafíos de seguridad regionales y globales.

- Apoyar las relaciones para abordar importantes amenazas terroristas en África: reforzando acuerdos bilaterales y asociaciones multilaterales con el objetivo de contener nuevas amenazas a los intereses de los Estados Unidos y contribuir a los desafíos de Europa y Medio Oriente (regímenes extremistas violentos, trata de personas, actividad criminal transnacional, comercio ilegal de armas, asistencia externa y limitación a la influencia de poderes no africanos). 
Así mismo, existen programas muy puntuales desarrollados por los Comandos Específicos desplegados a nivel mundial. Por ejemplo, Colombia participa activamente con Estados Unidos en un programa de cooperación en seguridad regional conjunta a través del Comando Sur (SOUTHCOM). Esta iniciativa llamada USCAP, invita a varios países amigos centroamericanos y del Caribe a intercambiar experiencias para contrarrestar las amenazas transnacionales que perturban la estabilidad y seguridad de la región. Colombia aporta su amplia experiencia, sus conocimientos y lecciones aprendidas a los estados que lo requieren, para elevar su nivel de seguridad y defensa y Estados Unidos facilita los recursos técnicos y económicos para la ejecución de actividades. En este momento el programa se enfoca en cuatro áreas clave: narcotráfico, lucha contra el crimen organizado, fortalecimiento institucional y fomento de comunidades más seguras (Baires, 2017).

De igual forma, se crean iniciativas bilaterales como el Plan Colombia, establecido en el año 2000 entre el gobierno estadounidense de Bill Clinton y el gobierno colombiano de Andrés Pastrana, como una alianza estratégica para luchar contra el narcotráfico en busca de fortalecer la institucionalidad, recuperar la seguridad y consolidar el desarrollo social en el país. Durante más de 15 años fueron invertidos más de 141 mil millones (10 mil millones invertidos por Estados Unidos y 131 mil millones invertidos por Colombia) para el fortalecimiento de las capacidades del sector de defensa (inteligencia e investigación criminal), así como la creación de centros de entrenamiento y capacitación y el mejoramiento de la capacidad operativa de las Fuerzas Armadas de Colombia que permitieron el debilitamiento de las redes de narcotraficantes y de los grupos armados al margen de la ley (Presidencia de la Repúbica de Colombia). Más allá de la recuperación de la seguridad, el Plan Colombia buscó implementar estrategias de inversión social para apoyar la población vulnerable, estas se tomaron con medidas de desarrollo económico regional que permitieron que Colombia cambiara su posición en la región, por ejemplo, la sustitución de cultivos.

Es evidente que Estados Unidos construyó una estrategia de seguridad mundial, a través del fomento de alianzas y coaliciones que le permite compartir sus mismos ideales como sociedad libre y Estado de Derecho, sin embargo, lo más importante de estas iniciativas a nivel mundial, es el establecimiento de unas reglas de juego internacionales claras y comunes, de acuerdo a sus propias necesidades de seguridad y defensa que les permita actuar bajo el enfoque de apoyo o asistencia sin ser cuestionados por una intervención (Dufort, 2017). 


\section{El Proceso}

\subsection{Contexto sistema político del país (régimen político para entender cuál es el proceso de elaboración de política pública)}

Estados Unidos cuenta con un sistema político3 de república presidencial federal constitucional 4 compuesta por 50 estados y con una constitución que data de 1789. El gobierno estadounidense está diseñado conforme a la división tripartita de poderes: ejecutivo, legislativo y judicial, que es la base de su sistema de checks and balances. En cuanto a los estados, cada uno cuenta con una constitución propia, división de poderes y amplio margen de autonomía política y administrativa derivadas del federalismo que impera en el país. El sistema político de Estados Unidos ha conocido una estabilidad casi permanente a lo largo de su historia (Universidad Nacional Autónoma de México).

El Poder Ejecutivo está encabezado por el Presidente, electo cada cuatro años, dentro de sus funciones se incluyen las de jefe de Estado y de Gobierno, su elección se realiza de forma indirecta, mediante la selección, por parte de los ciudadanos, de 538 electores, quienes son los encargados de designarlo. Puede ser reelegido en un único periodo. Dentro de sus facultades, el presidente funge como comandante de las Fuerzas Militares, así como conductor principal de la política exterior, tiene la libertad para proponer a todos los integrantes de su gabinete, nombrar y remover a los titulares de los distintos departamentos y agencias gubernamentales, tiene facultad de iniciativa (proponer proyectos de ley para su aprobación en el Congreso) así como el derecho de vetar las leyes que apruebe el legislativo, entre otras funciones (Universidad Nacional Autónoma de México).

Estados Unidos cuenta con un Poder Legislativo bicameral, compuesto por el Senado (Cámara Alta) y por la Cámara de Representantes (Cámara Baja). El Senado está integrado por 100 miembros electos por estados de la Federación, para un mandato de seis años (pueden ser reelectos de forma ilimitada). Cada estado elige dos representantes al Senado, sin tomar en cuenta el tamaño de su territorio o el número de habitantes. Por su parte, la Cámara de Representantes cuenta con 435 miembros, electos mediante sufragio universal, para lo que el país se divide en igual número de distritos electorales conforme a un criterio poblacional, su periodo es de dos años y pueden ser reelegidos de forma ilimitada (Universidad Nacional Autónoma de México).

Dado el sistema electoral estadounidense, de mayoría simple y el carácter descentralizado de sus dos partidos políticos, es común que los representantes y 
senadores gocen de un amplio margen de independencia en el ejercicio de su voto en la aprobación de leyes. Así, contrario de lo que sucede en otros países que utilizan este sistema, la disciplina de partido de los legisladores estadounidenses es más laxa (Universidad Nacional Autónoma de México).

Por su parte el Poder Judicial Federal de Estados Unidos está compuesto por la Suprema Corte de Justicia y por diversas cortes subsidiarias. La Corte Suprema de Justicia se integra por nueve ministros electos de forma vitalicia a propuesta del titular del Ejecutivo y con la aprobación por mayoría calificada de dos terceras partes del Senado. En el territorio estadounidense existen 12 circuitos federales, en cada uno de los cuales existe una Corte de Apelación para casos relacionados con leyes federales, delitos cometidos en dos o más estados, así como casos civiles y mercantiles que involucren leyes o ciudadanos de distintos estados. Además, existen 94 Cortes Federales de Distrito, que son los tribunales de primera instancia en relación con los litigios federales. Por su parte, los estados cuentan con cortes supremas, así como con distintos tribunales que manejan la mayoría de los litigios civiles y penales. Cada estado cuenta con legislación propia, así como con su grupo de abogados que certifica a los litigantes que pueden ejercer en la jurisdicción correspondiente (Universidad Nacional Autónoma de México).

Todo este sistema político recibe unas demandas por análisis de política que con el pasar del tiempo aumentan, no solo por el conocimiento especializado de algunos gremios y asociaciones, sino por la gestión de la complejidad del sector público (Weimer, 2015). El proceso federal de creación de regulaciones es la base del contenido sustantivo de las políticas públicas en Estados Unidos; también, se debe prestar especial atención cuando el país se encuentra polarizado permitiendo cuestionar cifras, presupuestos y estadísticas de un lado y otro.

En los temas de defensa y como fue explicado al inicio de este documento, las políticas de seguridad y defensa con producto del gobierno de turno, con una perspectiva a plazo medio (son revisadas cada uno o dos ańos) debido al entorno tan complejo en el que se formula y que puede cambiar con gran facilidad, agregado a esto debe tener unos recursos planeados para su correcta ejecución y debe ser alineada estratégicamente con la política exterior (compromisos bilaterales y multilaterales). Tal vez, la Estrategia Nacional de Seguridad (NSS) es un documento que no recibe la participación de actores externos, siendo formulada por actores estatales (principalmente el Departamento de Defensa y los asesores sobre el tema con que cuente el presidente), sin embargo, se formula bajo las preocupaciones de otros actores como el Legislativo, ONG's, académicos, think tanks, aliados internacionales, entre otros. 


\subsection{Análisis histórico de la evolución de la estrategia y/o política de seguridad nacional o libro blanco del país}

La Ley de Reorganización de Defensa (Goldwater-Nichols, 1986) estableció la presentación por parte del presidente de un informe anual sobre la Estrategia de Seguridad Nacional ( $99^{\circ}$ Congreso de los Estados Unidos, 1986), con el objetivo de dar coherencia a las orientaciones presupuestales, a los intereses y conceptos presentados al Congreso, dándole fundamento para apoyar su estrategia; pareciera que la formulación de dicha estrategia fuera un proceso racional y sistémico, sin embargo, la formulación de la Estrategia de Seguridad Nacional (NSS) requiere de un proceso político intenso, que resulta luego de una negociación prolongada entre la rama ejecutiva y la rama legislativa. Dicha estrategia establece los intereses, metas y objetivos mundiales de Estados Unidos que son vitales para su seguridad, así mimo, refleja la política exterior, los compromisos mundiales y las capacidades de defensa necesarias para disuadir la agresión, propone el uso del poder político, económico y militar a largo plazo para proteger y promover dichos objetivos y plantea la adecuación o transformación de algunas capacidades del país para apoyar su implementación.

La primera Estrategia presentada luego de promulgada la ley fue la del gobierno de Ronald Reagan en 1988, dicho documento fue preparado en un tiempo limitado que reflejó una estrategia limitada orientada al uso del poder militar para contener la amenaza que representaba la Unión Soviética, así mismo, generó más de 250 Directivas de Seguridad Nacional Clasificadas (NSDD), lo que representaba un conjunto de sub estrategias que no fueron eficaces como herramienta para lograr el respaldo presupuestal del Congreso ni el cumplimiento total de los objetivo de seguridad nacional (Snider, 1995, p. 12).

La segunda Estrategia fue presentada por el gobierno de George H.W. Bush en 1991 y diseñada con un enfoque de cambio global que incluía una detallada revisión interagencial. El cambio en el sistema internacional, marcado por Europa y Medio Oriente sirvió para que los tomadores de decisiones priorizaran la construcción de alianzas y coaliciones militares, algunas reglas sobre el armamento convencional y la disolución final del pacto de Varsovia. Desde esta estrategia se amplió el concepto netamente militar de la seguridad nacional y surgieron los nuevos términos de referencia para la disuasión nuclear. Políticamente, George H.W. Bush pretendió girar la brújula en el control de armas de este/oeste a norte/sur para ampliar su discusión más amplia sobre su proliferación. Y finalmente, este documento logró incluir el bienestar económico en la seguridad nacional, incluso 
programas más específicos como mejora de la competitividad, combate contra el comercio ilegal, déficit presupuestal, entre otros (Snider, 1995, p. 14).

Durante el segundo mandato de George H.W. Bush, se presentó en el año 1993 la tercera Estrategia. Sin embargo, este documento más que señalar el camino a futuro, fue un documento para documentar los logros del pasado. Esta estrategia se enfatizó en la transición constante y deliberada de una contención a un compromiso colectivo. En esta estrategia se estipuló el principio de paz democrática y la necesidad del liderazgo estadounidense para alcanzarlo en un mundo de interdependencias crecientes (Snider, 1995, p. 15).

En 1996 es publicada la cuarta Estrategia durante el gobierno de Bill Clinton con un aporte significativo a la organización de la Seguridad Nacional en el país y una gran base interinstitucional. Las operaciones militares, las cuestiones de seguridad económica, la influencia en el sistema económico internacional, las cuestiones de política exterior se convirtieron en los ejes de una gran estrategia, alcanzando un impacto en el extranjero con notables éxitos como el acuerdo GATT, el TLCAN, la desnuclearización de Rusia y Ucrania, las garantías de seguridad en Europa Central (Partners for Peace en la OTAN), un aparente acuerdo con Corea del Norte sobre la producción de plutonio; esta estrategia fue la primera en incorporar la seguridad estadounidense como la protección de su gente, su territorio y su forma de vida. Sus objetivos de seguridad se centraron en el mejoramiento de las condiciones de seguridad y defensa, la promoción de la prosperidad en el hogar y el fomento de la democracia (objetivos similares a los expuestos por Donald Trump en la Estrategia de Seguridad Nacional presentada en 2017) (Snider, 1995, p. 19).

Durante el periodo 2000 y 2001, bajo el mismo gobierno de Bill Clinton, fueron publicadas dos Estrategias respectivamente. La primera estrategia establecida en 1999 pero publicada en el año 2000, se centró en cuestiones internas, preservando y mejorando la disposición de las fuerzas militares mientras se perseguía la modernización a largo plazo y se buscaba mejorar la calidad de vida de hombres y mujeres uniformados. Para ese año fue incrementado el presupuesto de defensa, logrando un aumento en el salario militar y beneficios en los procesos de jubilación; igualmente la asignación presupuestal permitió una mayor preparación y modernización de otros requisitos de defensa de alta prioridad (The White House, 1999). Por su parte, los elementos clave de la Estrategia de Seguridad Nacional del año 2001, se resumieron en adaptar las alianzas de Estados Unidos, fomentar la reorientación de otros Estados, incluidos los antiguos adversarios, fomentar la democratización, la apertura de los mercados, el libre comercio y el desarrollo sostenible, la prevención del conflicto, contrarrestar posibles agresores regionales, enfrentar 
nuevas amenazas y dirigir operaciones internacionales de paz y estabilidad. Estos elementos son bloques de construcción dentro de una arquitectura estratégica que describe una política exterior para una era global. En esta estrategia se resumen dos principios: proteger los intereses y promover los valores (The White House, 2000) (Carrascal Jácome, Cortes Nieto \& Fernandez-Osorio, 2018).

Luego aparece la Estrategia de Seguridad Nacional, emitida por el primer gobierno George W. Bush, lanzada en medio de la controversia sobre la doctrina de guerra preventiva. Esta estrategia se formula como respuesta a la lucha contra el terrorismo e incorpora el concepto de preeminencia militar. Enfatiza en la ayuda externa, la cual sustancia a los países que se adhieren al modelo de democracia occidental. La doctrina Bush surge en el contexto de pasar de la vieja doctrina de disuasión de la Guerra Fría a un intento proactivo de ajustar la política a las realidades de la amenaza (desde actores estatales como un estado nación Irak o Irán, como actores no estatales Al Qaeda) (The White House, 2002).

Para el año 2006, el mismo gobierno, lanza un documento que se enfatiza en buscar y apoyar movimientos e instituciones democráticas en cada nación y cultura, con el objetivo final de terminar con la tiranía en el mundo, buscando crear un orbe de estados democráticos y bien gobernados que puedan satisfacer las necesidades de sus ciudadanos y comportarse de manera responsable en el sistema internacional. Esta es la mejor manera de proporcionar seguridad duradera para el pueblo estadounidense. Se centró en los regímenes totalitarios que basados en la perversión de la religión han violado los derechos humanos de sus poblaciones. Tenía varias tareas, entre ellas: defender las aspiraciones de la dignidad humana, fortalecer las alianzas para derrotar el terrorismo global, desactivar conflictos regionales, evitar amenazas con armas de destrucción masiva (ADM), iniciar una nueva era de crecimiento económico global a través de mercados libres, expandir el círculo de desarrollo abriendo sociedades y construyendo la infraestructura de la democracia, desarrollar agendas para la acción cooperativa y aprovechar las oportunidades y enfrentar los desafíos de la globalización (The White House, 2006).

En el año 2010, se publica la Estrategia de Seguridad Nacional del Presidente Barack Obama, la primera de su mandato. Este documento buscaba renovar el liderazgo de la nación, mediante la construcción y el cultivo de las fuentes de fuerza e influencia. Los intereses estadounidenses estipulados en esta estrategia fueron: la seguridad de los Estados Unidos, sus ciudadanos, aliados y socios; una economía fuerte, innovadora y en crecimiento; un sistema económico internacional abierto que promueva las oportunidades y la prosperidad; respeto de los valores universales y el liderazgo que promueva la paz, la seguridad y la cooperación a desafíos globales. 
Esta estrategia es fundamental para entender la transición de Estados Unidos en la guerra de Irak, Afganistán, Al Qaeda y el terrorismo, mientras promovió la recuperación económica después de una recesión catastrófica (The White House, 2010).

Finalmente, en el año 2015, durante el segundo mandato de Barack Obama, es lanzada la Estrategia de Seguridad Nacional que incorporó una variedad de amenazas no convencionales, diversificando la agenda de seguridad global y reafirmando el liderazgo de Estados Unidos. Los principales riesgos a los intereses fueron: ataques catastróficos en territorio de Estados Unidos o infraestructura crítica, amenazas o ataques contra ciudadanos de Estados Unidos y aliados en el exterior, crisis económica mundial o desaceleración generalizada de la economía, proliferación y uso de armas de destrucción masiva, epidemias graves de enfermedades infecciosas, cambio climático, interrupciones del mercado de energía, consecuencias significativas de seguridad asociadas con estados débiles o fallidos (incluidas las atrocidades masivas, el derrame regional y el crimen organizado transnacional), entre otras (The White House, 2015).

Actualmente, Estados Unidos cuenta con la Estrategia de Seguridad Nacional formulada por el Presidente Donald Trump y lanzada en el mes de diciembre de 2017, de la cual hemos hablado a lo largo de este documento; esta nueva orientación

determina a China y Rusia como poderes revisionistas mientras elimina al cambio climático como amenaza nacional. Este documento revela una administración con conflictos entre los impulsos aislacionistas y proteccionistas del Presidente y las creencias internacionalistas más tradicionales de sus antecesores (Obama y Bush).

\subsection{Protagonistas y procesos claves en la elaboración de los documentos}

La Estrategia de Seguridad Nacional de Estados Unidos lanzada por el Presidente Trump es el resultado de un trabajo intelectual principalmente de dos asesores: el asesor de Seguridad Nacional, el Teniente General HR McMaster y un miembro del Consejo de Seguridad Nacional, Nadia Schadlow (Benedicto, 2018, p. 3). Se debe recordar que las estrategias se redactan y se aprueban en el Consejo de Seguridad Nacional, su requerimiento no solo es por parte del Congreso, sino por varios actores de la sociedad civil como los think tanks, exfuncionarios del gobierno, profesionales asociados, los intelectuales, grupos de interés, entre otros. La formulación de la estrategia sigue una de las máximas más conocida de la comunidad política: "if we can agree on what we want, let's not try to agree on why we want it" (Snider, 1995, p. 8). 
Adicional a lo anterior, la Estrategia de Seguridad Nacional requiere de una construcción interagencial que represente las diferentes capacidades del poder nacional, tener acceso a la formulación de este documento, permite ingresar directamente a la agenda del Presidente.

Por otro lado, no se debe desconocer que la Estrategia busca comunicar la visión del Presidente al Congreso y así legitimar y fundamentar los recursos solicitados para la seguridad y defensa del Estado, pero esto no implica un debate sistemático, sino por el contrario, es el punto de partida para el consenso y entendimiento común a futuro. Es fundamental formular dicha estrategia en un lenguaje fácil y comprensible para lograr influir en la opinión del público sobre temas como la guerra, modernización estratégica, defensa, políticas regionales, entre otras. También, la Estrategia debe proponerse de acuerdo al contexto político interno e internacional, pues no debe olvidarse que este documento se constituye como una herramienta de transparencia internacional.

Así mismo, existe el proceso de planificación, programación, presupuesto y ejecución (PPBE), el cual se configura como uno de los tres procesos que conforman el Sistema de Adquisiciones de Defensa. Este se concentra en la gestión financiera y la asignación de recursos para los programas actuales y futuros establecidos por el Departamento de Defensa de los Estados Unidos. El proceso de PPBE consta de cuatro fases distintas, pero superpuestas:

- Planificación: es la definición y el examen de estrategias alternativas, el análisis de condiciones y tendencias cambiantes, amenazas, tecnología y evaluaciones económicas junto con esfuerzos para comprender, tanto el cambio como las implicaciones a largo plazo de las elecciones actuales.

- Programación: define y analiza estructuras de fuerzas alternativas, sistemas de armas y de apoyo junto con sus implicaciones de recursos de varios ańos y la evaluación de diversas opciones de compensación.

- Presupuestación: incluye la formulación, justificación, ejecución y control del presupuesto. El objetivo principal es estudiar los primeros dos años del presupuesto de un programa para garantizar un uso eficiente de los recursos.

- Ejecución: es la aplicación en el mundo real del proceso de Planificación, Programación, Presupuestación y Ejecución. 


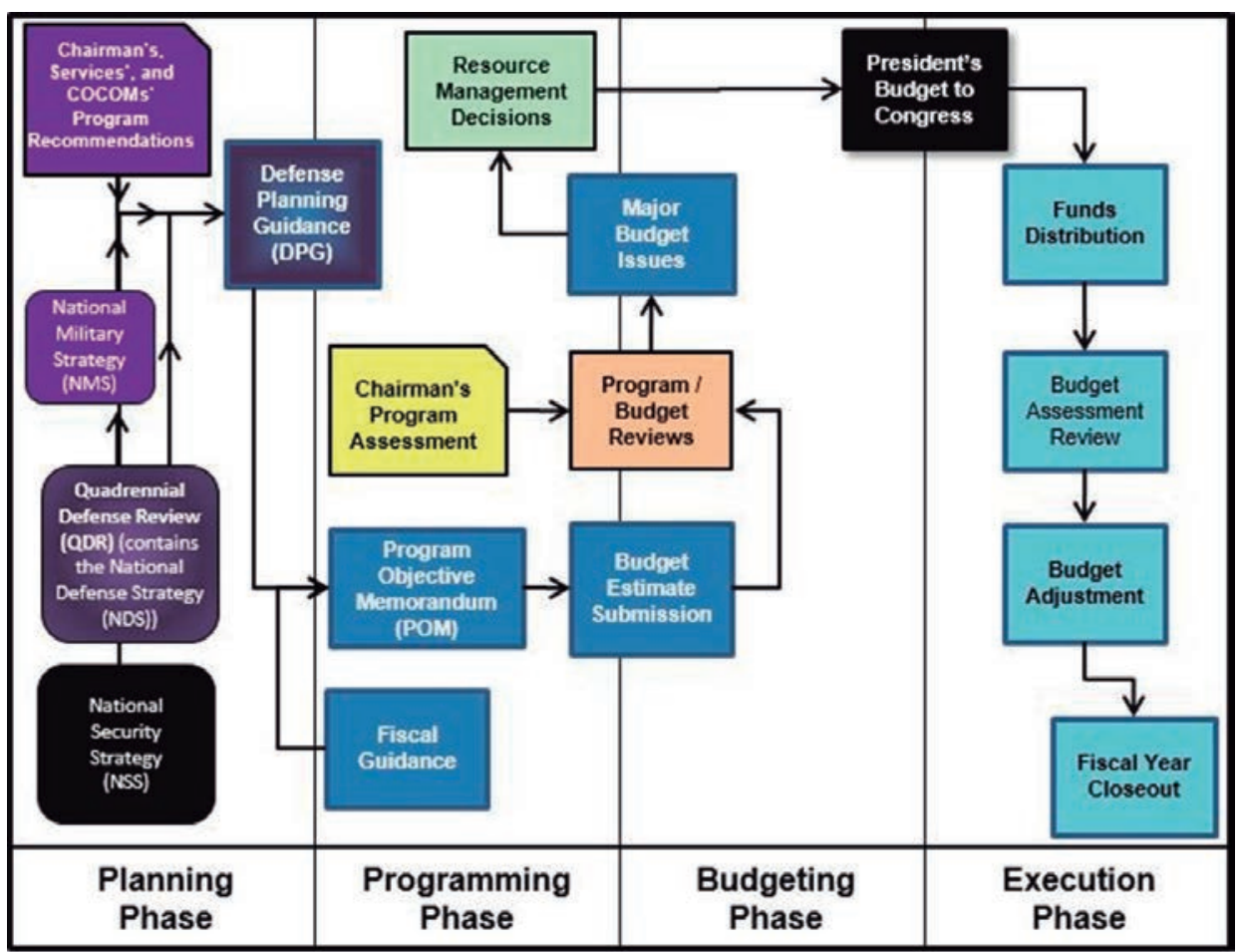

Figura 5: Descripción general del proceso de programación, presupuestación y ejecución (PPBE) Fuente: Defense Acquisitions Made Easy, 2016

\section{Conclusiones}

A través de los documentos analizados en el presente trabajo, es evidente observar que Estados Unidos cuenta con una cultura y pensamiento estratégicos en sus líderes políticos y tomadores de decisiones, formados con unos determinantes geopolíticos y geoestratégicos claros que les permiten relacionar el poder militar con el mantenimiento del liderazgo mundial e incorporar al concepto de Seguridad Nacional, todos los sectores del gobierno y campos del poder.

Durante la revisión de las Estrategias de Estados Unidos, es común encontrar una perspectiva integradora en la que todos los instrumentos disponibles, ya sean del Estado, del sector privado o de la comunidad civil, han de ser usados en cooperación con socios y aliados para garantizar un escenario caracterizado por la incertidumbre y la complejidad.

Igualmente, se hace evidente el papel que tienen las Fuerzas Militares en la elaboración de dicha Estrategia, que recordemos, da la orientación para la formula- 
ción de otros documentos en diferentes niveles (Estrategia de Defensa, presupuesto de defensa, entre otros). A través del poder militar, Estados Unidos ha mantenido su liderazgo en varias cuestiones mundiales y presencia en casi todo el mundo, a través de sus capacidades y redes de aliados y socios. Unas Fuerzas Militares entrenadas, capacitadas, modernas y más letales le permitirán enfrentar amenazas y riesgos más heterogéneos, interdependientes, trasnacionales y dinámicos, por lo que se requieren respuestas de anticipación, prevención y resiliencia ante la imprevisibilidad de las mismas. Además, cabe resaltar que las Fuerzas Militares han liderado los procesos de industrialización y han generado una base de innovación, a través de ciencia y tecnología, que posicionan al país como pionero en muchos programas no solo militares (de armas) sino médicos, de infraestructura, sostenibilidad ambiental, entre otros (Chavarro Miranda, Grautoff Laverde \& Riaño Cruz, 2017; Álvarez Calderón \& Rodríguez Beltrán, 2018).

Es fundamental considerar la inseguridad económica como una amenaza a la seguridad nacional. Para ello, la última Estrategia de Estados Unidos fue formulada bajo la premisa "America Fisrt" con algunas medidas proteccionistas y aislacionistas, que pretenden recuperar la economía nacional.

En definitiva, es la Estrategia de Seguridad Nacional una gran táctica que conjuga la seguridad y defensa con la política exterior del país e incorpora la visión a futuro del poder nacional en un campo internacional.

\section{Referencias}

99 ${ }^{\circ}$ Congreso de los Estados Unidos. (1986). Ley Goldwater-Nichols. Recuperado el 3 de Abril de 2018 de http://history.defense.gov/Portals/70/Documents/dod_reforms/GoldwaterNicholsDoDReordAct1986.pdf

Álvarez Calderón, C., \& Rodríguez Beltrán, C. (2018). Ecosistemas criminales. Revista Científica General José María Córdova, 16(24), 1-30. https://doi.org/10.21830/19006586.352

Ardila Castro, C., \& Rodríguez, J. (2018). Visión geoestratégica china y su incidencia sobre Latinoamérica y África. Revista Científica General José María Córdova, 16(23), 1-22. https://doi. org/10.21830/19006586.303

Baires, L. (2 de Marzo de 2017). USCAP, estrategia regional contra amenazas transnacionales. Recuperado el 29 de Marzo de 20018 de Diálogo Revista Militar Digital https://dialogo-americas.com/es/articles/ uscap-regional-strategy-against-transnational-threats

BBC Mundo. (16 de Marzo de 2017). 8 gráficos que comparan el poderío militar de Estados Unidos y China. Recuperado el 30 de Marzo de 2018 de Noticias Internacionales http://www.bbc.com/mundo/ noticias-internacional-39274331\#orb-banner

Benedicto , M. (26 de Enero de 2018). Trump y su estrategia de Seguridad Nacional: una "contradictio in terminis". Recuperado el 20 de Febrero de 2018 de Documento Opinión - Instituto Español de 
Estudios Estratégicos http://www.ieee.es/Galerias/fichero/docs_opinion/2018/DIEEEO09-2018_ Trump_y_ESN_Miguel_Angel_Benedicto.pdf

Blakeley, K. (3 de Agosto de 2017). Overview of the FY 2018 Defense Budget Request. Recuperado el 28 de Marzo de 2018 de Center for Strategic and Budgetary Assesments - CBSA http://csbaonline.org/ reports/overview-of-the-fy-2018-defense-budget-request

Borda, S. (Julio de 2013). Estados Unidos o el último Estado hegemónico. El poder en la era del ascenso y la consolidación del resto del mundo. Recuperado el 5 de Enero de 2018 de Nueva Sociedad: Democracia y política en América Latina: http://nuso.org/media/articles/downloads/1_3953.pdf

Campins Rahan, M. (2004). El significado de la seguridad nacional en Estados Unidos. Boletín de Información - Ministerio de Defensa (283). Recuperado el 5 de Enero de 2018 de Dialnet Universidad de la Rioja : https://dialnet.unirioja.es/descarga/articulo/4580036.pdf

Carrascal Jácome, M., Cortes Nieto, Y. \& Fernandez-Osorio, A. (2018). (Ed.). Operaciones de mantenimiento de la paz: aproximación a un sistema nacional. Bogotá D.C.: Sello Editorial ESMIC

Chavarro Miranda, F., Grautoff Laverde, M., \& Riańo Cruz, J. (2017). Modelo de crecimiento económico y gasto público focalizado en seguridad: enfoque desde la estrategia militar en Colombia (2002-2009). Revista Científica General José María Córdova, 15(20), 27-45. https://doi. org/10.21830/19006586.174

Chief Financial Officer (2018). Defense Budget Overview fiscal year 2019. Recuperado el 27 de Marzo de 2018 de http://dcmo.defense.gov/Publications/AnnualPerformancePlanandPerformanceReport.aspx.

Department of Defense (2018). Summary of the National Defense Strategy of the United States of America. Recuperado el 21 de Febrero de 2018 de Documents https:/www.defense.gov/Portals/1/ Documents/pubs/2018-National-Defense-Strategy-Summary.pdf

Department of State (26 de Julio de 1947). National Security Act. Recuperado el 02 de Marzo de 2018 de National Archives Catalog site https://catalog.archives.gov/id/299856

Department of the Navy (s.f.). Command Directory. Recuperado el 29 de Marzo de 2018 de About.

Dufort, P. (2017). La influencia de la comprensión cambiante del poder sobre la estrategia: un ensayo genealógico. Revista Científica General José María Córdova, 15(19), 29-81. https://doi. org/10.21830/19006586.83

Fernandez-Osorio, A. (2015). Full Spectrum Operations: the Rationale Behind the 2008 Russian Military Reform?. Revista Científica General José María Córdova, 13(15), 63-86. https://doi. org/10.21830/19006586.11

Font, T. \& Ortega, P. (2012). Seguridad Nacional, Seguridad multidimensional, Seguridad Humana. Papeles de relaciones ecosociales y cambio global (119), 161 - 172. Recuperado de http://www. fuhem.es/media/cdv/file/biblioteca/revista_papeles/119/Seguridad_nacional_multidimensional_ humana_T._Font_y_P._Ortega.pdf

Instituto Español de Estudios Estratégicos - IEEE (Julio de 2010). Documento de análisis No.06/2010. Recuperado de la Estrategia de Seguridad Nacional de los Estados Unidos http://www.ieee.es/ Galerias/fichero/2010/DA-IEEE_06-2010_NSS_2010_ASPECTOS_DESTACADOS_DE_SU_ EVOLUCION.pdf

Instituto Español de Estudios Estratégicos (2017). Panorama Estratégico 2017. España: Ministerio de Defensa . Recuperado el 26 de Marzo de 2018 de http://www.ieee.es/Galerias/fichero/panoramas/ Panorama_Estrategico_2017.pdf 
Joint Chiefs of Staff (2017). Doctrine for the Armed Forces of the United States. Recuperado el 19 de Febrero de 2018 de http://www.jcs.mil/Portals/36/Documents/Doctrine/pubs/jp1_ch1.pdf?ver=2017-1223-160207-587

Laborie, M. (01 de Febrero de 2018). "America First" ¿un modelo válido de seguridad nacional para los Estados Unidos? Documento de Opinión - Instituto Español de Estudios Estratégicos (10/2018), 1-15. Recuperado el 19 de Febrero de 2018 de http://www.ieee.es/Galerias/fichero/docs_opinion/2018/ DIEEEO10-2018_Estrategia_US_MarioLaborie.pdf

Montero Moncada, L. (2006). Política exterior de Seguridad Estadounidense en la post-Guerra Fría y el Mundo Post 11 de Septiembre. Revista de Relaciones Internacionales, Estrategia y Seguridad, 1(2 (julio-diciembre)), $105-120$.

Naciones Unidas (2004). Oficina contra la Droga y el Delito. Recuperado el 5 de Enero de 2018 de Convención de las Naciones Unidas contra la Delincuencia Organizada Transnacional y sus protocolos: https://www.unodc.org/pdf/cld/TOCebook-s.pdf

Naím, M. (2003). Las cinco guerras de la globalización. Foreign Policy, Diciembre - Enero, 33 - 41.

National Guard (s.f.). About the Guard. Recuperado el 29 de Marzo de 2018 de National Guard: http:// www.nationalguard.mil/About-the-Guard/

National Security Strategy Archive (4 de Enero de 2018). NSS Reports . Obtenido de http://nssarchive.us/

Organización de los Estados Americanos (23 de Octubre de 2003). Conferencia Especial sobre Seguridad.

Recuperado el 5 de Enero de 2018 de Declaración sobre Seguridad en las Américas https://www. oas.org/36ag/espanol/doc_referencia/DeclaracionMexico_Seguridad.pdf

Páez Murillo, C., Peón Escalante, I., \& Ramírez Pedraza, Y. (2018). Contexto de la seguridad ciudadana en América Latina y el Caribe. Revista Científica General José María Córdova, 16(24), 83-106. https://doi.org/10.21830/19006586.360

Presidencia de la Repúbica de Colombia (s.f.). 15 años del Plan Colombia. Recuperado el 25 de Marzo de 2017 de Especiales http://especiales.presidencia.gov.co/Documents/20160204-plan-colombia/ plan-colombia.html\#nueva-colombia

Snider, D. (1995). La Estrategia Nacional de Seguridad: documentando la visión estratégica. Instituto de Estudios Estratégicos del Ejército de los Estados Unidos. Recuperado el 3 de Abril de 2018 de http://nssarchive.us/wp-content/uploads/2012/05/Snider.pdf\&xid=25657,15700021,15700124, $15700149,15700168,15700186,157$

Stein, A. (2009). El concepto de Seguridad multidimensional. Bien común, $15(176$ - 177), 31 - 37.

The Secretary of the Navy (2018). Strategic Documents. Recuperado el 20 de Febrero de 2018 de Department of the Navy site http://www.navy.mil/strategic/SECNAV-Spencer-DoN-Vision-2017.pdf

The White House (1999). A National Security Strategy for a new century. Recuperado el 29 de Marzo de 2018 falta el link

The White House (2000). A National Security Strategy for a Global Age. Recuperado el 29 de Marzo de 2018 falta el link

The White House (2002). The National Security Strategy of the United States of America. Recuperado el 29 de Marzo de 2018

The White House (2006). The National Security Strategy. Recuperado el 29 de Marzo de 2018

The White House. (2010). National Security Strategy. Recuperado el 29 de Marzo de 2018 
The White House (2015). National Security Strategy. Recuperado el 29 de Marzo de 2018

The White House (2017). National Security Strategy of the United States of America. Recuperado el 26 de Marzo de 2018

U.S. Army (2018). Organization. Recuperado el 20 de Febrero de 2018 de U.S. Army site https://www. army.mil/info/organization/

United States Coast Guard (s.f.). Organization. Recuperado el 29 de Marzo de 2018,de United States Coast Guard https://www.uscg.mil/Units/Organization/

Universidad Nacional Autónoma de México (s.f.). Sistema Politico de Estados Unidos. Recuperado el 31 de Marzo de 2018 de Archivos Jurídicos https://archivos.juridicas.unam.mx/www/bjv/ libros/2/525/4.pdf

US Air Force (s.f.). About Us. Recuperado el 29 de Marzo de 2018 de U.S. Air Force http://www.af.mil/ About-Us/

Weimer, D. (Abril/Junio de 2015). La evolución del análisis de políticas en Estados Unidos: cuatro fuentes de demanda. Foro Internacional, 55(2), 540 - 574. Recuperado el 29 de Marzo de 2018 de http:// www.scielo.org.mx/pdf/fi/v55n2/0185-013X-fi-55-02-00540.pdf

Withers, G., Isacson, A., Haugaard, L., Olson, J. \& Fyke, J. (Fe de 2008). Latin America Working Group Education Fund. Recuperado el 19 de Febrero de 2018 de Documents http://www.lawg.org/ storage/documents/ready\%20aim\%20espanol.pdf 